\title{
Article \\ Influence of Ag Electrodes Asymmetry Arrangement on Their Erosion Wear and Nanoparticle Synthesis in Spark Discharge
}

\author{
Kirill Khabarov*(D), Maxim Urazov, Anna Lizunova (D), Ekaterina Kameneva, Alexey Efimov (D) and Victor Ivanov \\ Department of Physical and Quantum Electronics, Moscow Institute of Physics and Technology, National \\ Research University, 141701 Dolgoprudny, Russia; desperate@inbox.ru (M.U.); Lizunova.aa@mipt.ru (A.L.); \\ katerinakamenev@yandex.ru (E.K.); efimov.aa@mipt.ru (A.E.); ivanov.vv@mipt.ru (V.I.) \\ * Correspondence: kirill.khabarov@phystech.edu
}

Citation: Khabarov, K.; Urazov, M.; Lizunova, A.; Kameneva, E.; Efimov, A.; Ivanov, V. Influence of Ag

Electrodes Asymmetry Arrangement on Their Erosion Wear and Nanoparticle Synthesis in Spark Discharge. Appl. Sci. 2021, 11, 4147. https://doi.org/10.3390/app11094147

Academic Editor: Mariusz Jasiński

Received: 29 March 2021

Accepted: 29 April 2021

Published: 1 May 2021

Publisher's Note: MDPI stays neutral with regard to jurisdictional claims in published maps and institutional affiliations.

Copyright: (c) 2021 by the authors. Licensee MDPI, Basel, Switzerland. This article is an open access article distributed under the terms and conditions of the Creative Commons Attribution (CC BY) license (https:// creativecommons.org/licenses/by/ $4.0 /)$.

\begin{abstract}
For nanoparticle synthesis in a spark discharge, the influence of the degree of electrode asymmetry in the rod-to-rod configuration, using the example of silver electrodes, on the energy efficiency and nanoparticle composition is studied. The asymmetry degree was determined by the angle between electrodes' end faces. Two types of discharge current pulses were used: oscillationdamped and unipolar, in which electrodes changed their polarities and had a constant polarity during a single discharge, respectively. A significant influence of the asymmetry degree of the electrode arrangement on the synthesized nanoparticle size, agglomeration and concentration, and on the synthesis energy efficiency, has been established. An increase in the degree of the electrode asymmetry with the oscillation-damped discharge current pulse led to an increased mass production rate and energy efficiency of nanoparticle synthesis, a significant fraction of which had large dimensions of more than $40 \mathrm{~nm}$. The effect of the transfer of synthesized nanoparticles to the opposite electrode at the unipolar discharge current pulse led to the appearance of electroerosive instability, manifested in the formation of a protrusion on the anode surface, around which spark discharges, leading to its further growth and electrode gap closure.
\end{abstract}

Keywords: spark discharge; nanoparticle synthesis; silver electrodes; electrodes asymmetry

\section{Introduction}

A spark discharge (SD) [1,2] is a good method for producing nanoparticles (NPs) of small size (less than $20 \mathrm{~nm}$ ) by the electrical erosion [1] of the electrode material [3] with a fast response due to instantaneous changes in the parameters of the electrical discharge circuit [4]. In the SD processes, high-energy spark discharges are created between two electrodes in a controlled gasflow, eroding the electrode material and forming NPs in the form of aerosol [5]. A large set of SD parameters makes it possible to fine-tune the shape, size, and concentration of the synthesized NPs. For instance, this method can be applied for NP synthesis for the purpose of formation and doping of multicomponent structures: metal alloys [6,7], semiconductor quantum dots [8-11], optical and magnetic materials [12], and high-temperature superconductors [13,14]. Additionally, the method is convenient for manufacturing devices for microelectronics and photonics [15], gas [16,17] and biological sensors [18] based on NPs, microconductors, resistors [19,20] and capacitive elements [2]. However, incorrect selection of method parameters leads to non-optimal use of the discharge energy [21] and the production of large parasitic particles (more than $40 \mathrm{~nm})$.

SD parameters, determining the diversity of NPs and the stability of their synthesis, have been studied by different methods, but there are still questions that require detailed consideration. Thus, the authors of $[4,22]$ studied the size and shape dependence of the synthesized particles from the discharge pulse energy, frequency of discharge repetition, and parameters of the carrier gas, such as the composition, flow rate, pressure, and temperature of the gas medium [23-25]. For example, the energy released in the discharge 
and the pulse repetition rate are both key parameters that strongly influence the size, shape, and concentration of the synthesized NPs [8]. However, determining the exact value of the energy in the discharge is a complex experimental task, solved by measuring the current and voltage in the interelectrode gap in SD processes for NP synthesis [4] and for micro-electro discharge machining (EDM) $[26,27]$. The authors of [4] were measuring pulsed voltage across the interelectrode gap and proposed an algorithm for determining the energy transferred into the discharge gap. In the paper [26] Yang et al. received the spark discharge waveforms in the gap and presented a model for the micro-EDM parameters' prediction. D'Urso et al. [27] performed a method for the evaluation of discharge parameters and investigated their influence and the influence of electrode size on stainless steel drilling by micro-EDM. A simpler approach is to estimate the energy released in the spark gap by approximating the active impedance of the gap with an equivalent constant electrical resistance $[1,5]$.

Additionally to the energy parameters, the influence of the electrodes' relative position and the gas flow blowing past them on the synthesis of particles is of great interest. There are many configurations of the electrode arrangement for spark discharge generators (SDG): rod-to-rod, rod-to-tube, pin-to-plate, wire-in-hole, and wire-to-hole [28,29]. Each of them requires precise adjustment and control of the electrodes' positions. For instance, in wirein-hole and wire-to-hole configurations with a wire thickness of about $0.5 \mathrm{~mm}$, it is quite difficult to stabilize the position of the wire electrode in the gas flow. Thus, in the work [30], electrodes were constantly adjusted to prevent the electrical circuit break. Currently, the rodto-rod configuration is the most common. It involves a pair of cylindrical electrodes fixed in crimping holders and separated by a gap [31]. At the same time, this configuration is the least demanding for the electrodes' setup accuracy for the purpose of particle synthesis repeatability. The influence of the electrodes' position relative to the gas flow on the size and shape of particles and their agglomerates was studied experimentally and by computer modeling methods by the authors of [32]. It was also found that the diameter of rod-shaped electrodes significantly affects the energy efficiency of NP synthesis [21].

In this paper, we study the influence of another important parameter on the processes of NP synthesis in the SD-the degree of asymmetry of the electrode arrangement in the rod-to-rod configuration on the example of silver electrodes. The two types of discharge current pulses were studied-oscillation-damped, in which the electrodes changed their polarities during a single discharge, and unipolar, in which the electrodes had a given polarity during the discharge. Electrodes in the form of rods, one of which had a gas supply hole, were installed coaxially. The end faces of the installed electrodes, from which the electrical erosion of the material was performed during the discharge current flow, were oriented in parallel and at an angle. Here, the parameters of the gas flow and the capacitor initial energy were the same in these experiments.

\section{Materials and Methods}

In this paper, we study the changes in the size and morphology of silver NPs obtained in the SD on different setup variants for electrodes' working surfaces and on changes in parameters of the SDG electrical circuit. A schematic representation of the SDG setup is shown in Figure 1a. The SD was formed between two coaxially exposed cylindrical silver electrodes with a diameter of $8 \mathrm{~mm}$, along the axis of one of which a cylindrical hole with a diameter of $1.4 \mathrm{~mm}$ was made to supply a gas flow into the interelectrode gap. The distance between the two nearest points of electrodes was initially set to $1 \mathrm{~mm}$. The electrical part of the SDG circuit was implemented in two different versions-with an additional ballast resistor with a nominal resistance of $5.0 \Omega$, causing a unipolar discharge current pulse (UDP), and without it, causing an oscillation-damped discharge current pulse (ODP). In each case, the voltage waveform on the capacitor during a discharge was recorded by the oscilloscope DPO4102B-L (Tektronix, Beaverton, OR, USA) with an upper limit frequency of $20 \mathrm{MHz}$ on a fast scan from a RC-voltage divider with an upper limit frequency of about $7 \mathrm{MHz}$. Since the ODP and UDP correspond to the oscillations with a positive value 
of the square of the present frequency $\omega^{2}=\omega_{0}^{2}-\gamma^{2}>0$ (with $\omega^{2} \rightarrow+0$ for the UDP case), the signal form is well described by the damped cosine function in the experiment (Figure 2) [33]:

$$
U=U_{c} e^{-\gamma t} \cos \omega t
$$

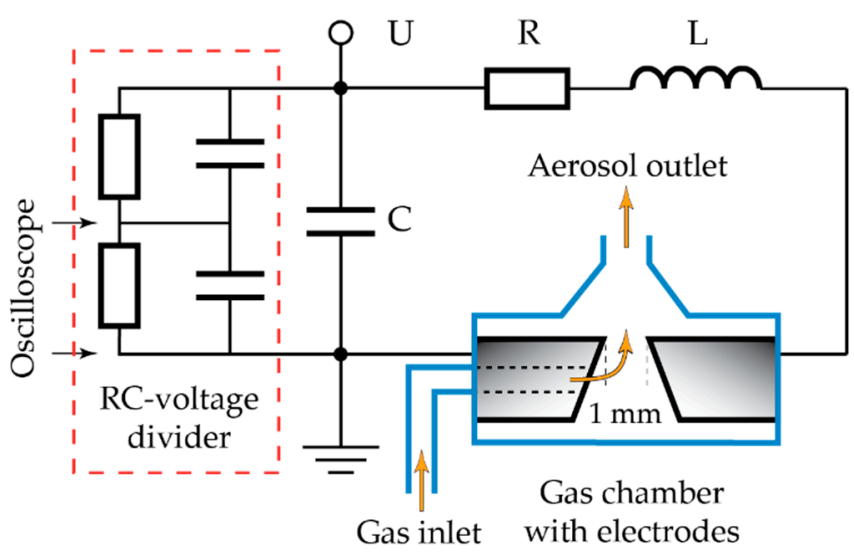

(a)
1)

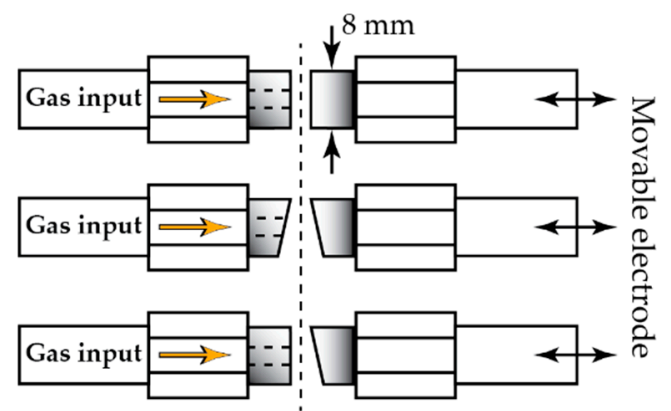

(b)

Figure 1. Equivalent representation of (a) the SDG setup and (b) of electrodes with the different position of their ends: (1) installed in parallel and at an angle for the experiments with (2) the ODP and (3) the UDP.

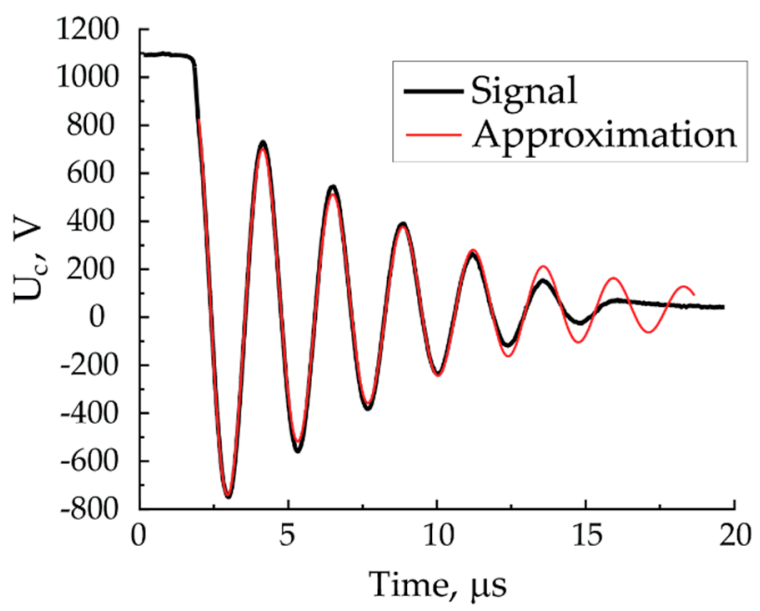

(a)

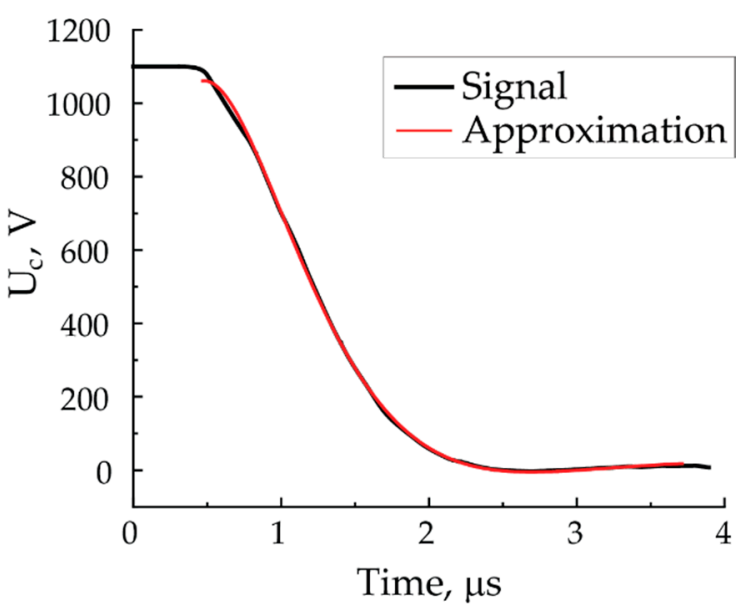

(b)

Figure 2. Waveforms of the voltage pulse (a) without and (b) with a ballast resistor in the electrical circuit for the symmetrical position of electrodes.

Here and next, $U_{c}$ stands for the voltage amplitude, $t$ for time, $\gamma=R_{e}(2 L)^{-1}$ for the damping coefficient, $\omega_{0}=(L C)^{-0.5}$ for the natural frequency of harmonic oscillations, $R_{e}=R+R_{s}$ for the total equivalent electrical resistance of the discharge circuit, represented as the sum of the equivalent electrical resistances of the discharge circuit $R$ and of the spark gap $R_{s}$, and $L$ and $C$ for circuit inductance and capacitance, respectively.

NP synthesis during the erosion of electrodes was done in a T-shaped chamber made of refractory glass (Duran, Milville, NJ, USA) in an argon atmosphere $(99.9999 \%$ ) at an excess pressure of $10 \mathrm{kPa}$, recorded by a pressure gauge, with a gas flow rate of $200 \mathrm{~mL} / \mathrm{min}$, recorded by the flow meter RRG-12 (Eltochpribor, Zelenograd, Russia).

The experiments were conducted in the mode of the interelectrode gap electrical breakdown. The nominal value of the discharge capacitor was $C=107 \mathrm{nF}$, the initial values of the capacitor charging voltage and frequency of capacitor discharges were $U_{c}=1100 \mathrm{~V}$ and $v=500 \mathrm{~Hz}$, respectively. In the case of the ODP, the electrical resistance $\mathrm{R}$ and the 
inductance $L$ of the discharge circuit, without active loss in the interelectrode gap, were determined by the corresponding parasitic values in wires and in the capacitor. In the case of the UDP, a ballast-cooled resistor with a nominal value of $5.0 \Omega$ was additionally installed. Approximating the discharge voltage waveforms for the symmetrical position of electrodes (Figure 2) with the function (1), the unknown equivalent total electrical resistance and inductance of the discharge circuit, including the spark gap, were $L=1.31 \mu \mathrm{H}, R_{e}=0.40 \Omega$ and $L=1.97 \mu \mathrm{H}, R_{e}=6.16 \Omega$ for the ODP and UDP, respectively. Electrical resistances of the discharge circuit $R=0.13 \Omega$ and $5.55 \Omega$ with the ODP and UDP, respectively, were measured at the natural frequency of discharge current oscillations by the impedance spectrometer RLC-meter AMM-3058 (AKTAKOM, Santa Clara, CA, USA). In this case, current and potential contacts of the device were connected to symmetrically arranged electrodes at ends facing each other. Taking into account these measurements, equivalent electrical resistances of the interelectrode spark gap were $0.27 \Omega$ and $0.61 \Omega$ for the ODP and UDP, respectively.

At the beginning of each experiment, electrodes' surfaces, intended for the electroerosive NP synthesis, were polished on the grinding and polishing machine Digiprep Accura (Metkon, Bursa, Turkey) to a roughness of $\mathrm{Ra}=0.5 \mu \mathrm{m}$. The average electrode roughness was measured by the optical profilometer $\mathrm{S}$ neox (Sensofar, Terrassa, Spain) on the confocal $20 \times$ lens from the area $800 \times 800 \mu \mathrm{m}^{2}$.

In the experiments, electrodes were arranged coaxially and their nearest end faces were located parallel (at the angle of $0^{\circ}$ ) and at the angles of $7^{\circ}$ and $15^{\circ}$ for the ODP and parallel (at the angle of $0^{\circ}$ ) and at the angles of $3^{\circ}$ and $10^{\circ}$ for the UDP. Assuming that the electrode with a positive potential does not undergo significant erosion in the case of the UDP, only cathode end face was beveled, whereas in the case of the ODP, ends of both electrodes were set at an angle (Figure 1b).

NPs were synthesized in the process of electrode erosion by a pulse-periodic SD continuously for $6 \mathrm{~h}$ maximum. During this experiment, we studied the statistical size distribution of silver NP agglomerates in the aerosol stream by their differential electrical mobility via the aerosol NP analyzer SMPS 3936 (TSI Inc., Shoreview, MN, USA). The statistical agglomerate size distribution was described by a log-normal distribution. The time dependence of the NP agglomerates modal size during electrode wear was constructed from distributions maxima. In parallel, we recorded changes in the capacitor charging voltage and the frequency of capacitor discharges in the setup by oscillograph readings. In addition, samples of the synthesized NPs were studied by the transmission electron microscope (TEM) JEM-2100 (JEOL, Ltd., Tokyo, Japan) for each regime under the study. For that purpose they were deposited on TEM grids in 5-10 min intervals from the start of experiments and after the establishment of thermodynamic equilibrium in the spark gap. Based on the TEM images, we collected statistics on the NPs size for at least 1000 pieces approximating them by round particles of equivalent cross-sectional area and drew their size distribution. At the end of experiments, we investigated electrodes' end faces after their electrical erosion, and their elemental composition in the scanning electron microscope (SEM) JSM 7001F (JEOL, Ltd., Tokyo, Japan) with the option of energy dispersive X-ray spectroscopy (EDX).

At the beginning and in the end of each experiment, we weighed electrodes on the scale SQP-F SECURA 225D-1ORU (Sartorius Lab Instruments, Goettingen, Germany) with a resolution of $10 \mu \mathrm{g}$ to estimate the electrodes' mass loss as a result of their erosion.

\section{Results}

Installing electrodes in the synthesis chamber of SDG, it is difficult to avoid some asymmetry in their relative positions. The appearance of random angles between the planes of erosion ends of electrodes leads to a change in the composition of synthesized NPs and to non-reproducible results. In the present study, we purposely set a certain degree of electrode asymmetry and evaluated its effect on the size, shape and concentration of NPs, as well as the energy efficiency of synthesis with the ODP in which the electrodes 
changed their polarities during a single discharge, and UDP, in which the electrodes had a given polarity during the discharge.

\subsection{The Influence of the Degree of Electrodes Asymmetry on the NP Synthesis with the ODP}

The characteristic side view of an electrode pair installed in the discharge chamber, with end faces located at the angle of $15^{\circ}$ to each other, is shown in Figure 3 for the three cases of the ODP: the initial position before the SD process, during the SD process, and $6 \mathrm{~h}$ after the SD process. As it can be seen from Figure 3b, the SD is localized in the region of the shortest distance between the electrodes, which is characteristic of the electric breakdown of gas gaps. Figure $3 c$ shows a significant wear of the beveled end faces of both electrodes during $6 \mathrm{~h}$ of processing: the ends were aligned during this time to a parallel state. Photos of the electrodes end faces, SEM images of their surface characteristic areas (types 1-3 in Figure $4 \mathrm{a}-\mathrm{c}$ ) and chemical composition of the obtained surfaces for the cases of electrodes parallel location and location at the angle of $15^{\circ}$ are shown in Figure 4. Moreover, the surface characteristic areas of type 3 are similar to each other for the cases of parallel orientation (Figure $4 \mathrm{~b}$ ) and at an angle (Figure $4 \mathrm{c}$ ).

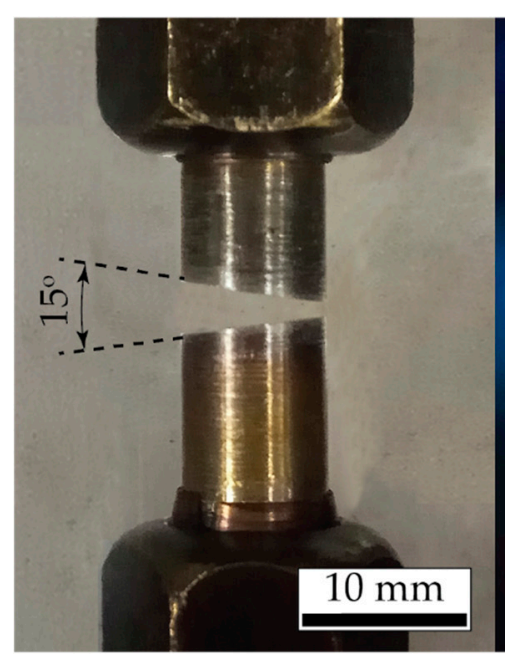

(a)

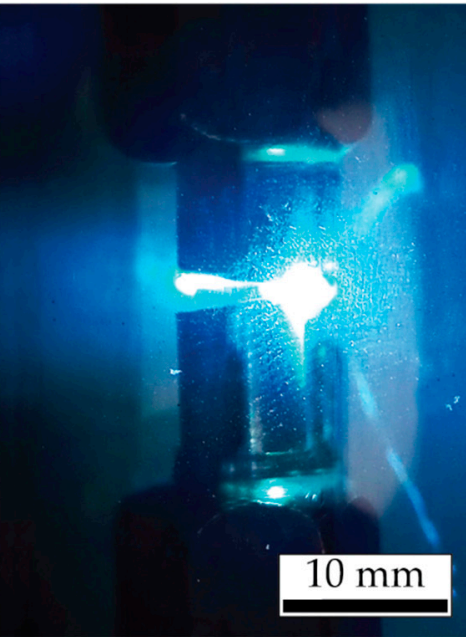

(b)

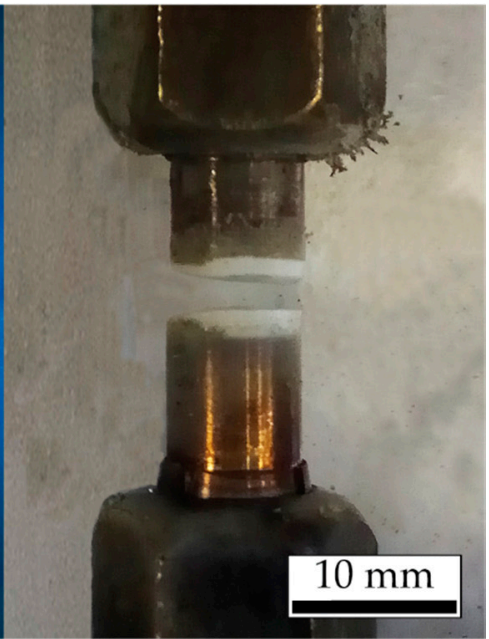

(c)

Figure 3. Photos of the gap between the electrodes with end faces forming the angle of $15^{\circ}$ : (a) before the start of the SD process, (b) during the discharge process and (c) $6 \mathrm{~h}$ after the spark treatment by the ODP.

The SEM image of area 1 of Figure 4a shows a typical surface of the original polished electrode, characterized by an average roughness of $\mathrm{Ra}=0.5 \mu \mathrm{m}$. On the electrodes' end faces, initially located at the angle of $15^{\circ}$ (Figure $4 \mathrm{~b}$ ), after processing with the SD, two typical areas marked in the Figure $4 \mathrm{~b}$ with the numbers 2 and 3 are observed. As it can be seen from the SEM image of the area 2, the polished surface of the electrode is covered with a loose layer of dendrite-like NP agglomerates. Presumably, the main part of such agglomerates was formed with electrical erosion and transferred from the opposite electrode. Area 3 represents exactly the electrode surface treated with the SD, and as it can be seen from the SEM image, it consists of overlapping craters with dimensions of about $10 \mu \mathrm{m}$. Each subsequent discharge, leading to the formation of a new crater, can occur in places of increased electric field density on microprotrusions formed over the previous crater edge as a result of spilling molten metal. The elemental composition of Ag electrode surfaces, according to the results of EDX (Figure $4 \mathrm{~g}-\mathrm{i}$ ), dominantly consist of silver for all cases, presented in Figure $4 a-c$. In this case, the presence of carbon may be associated with the presence of carbon-containing compounds in the carrier gas and adsorbed substances in the gas discharge chamber and on the initial electrodes. 


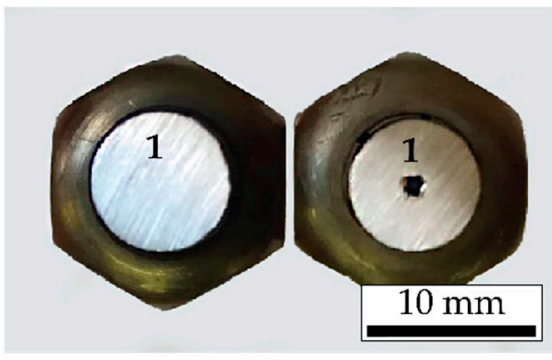

(a)

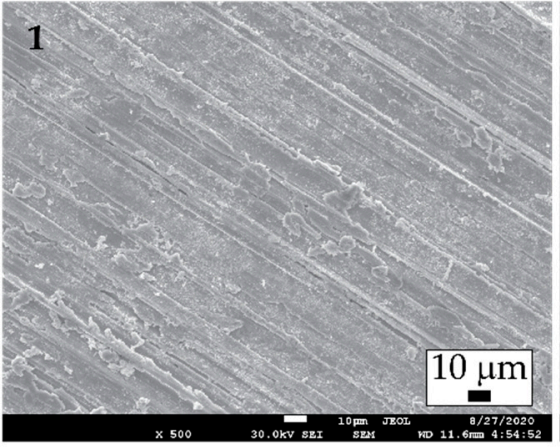

(d)

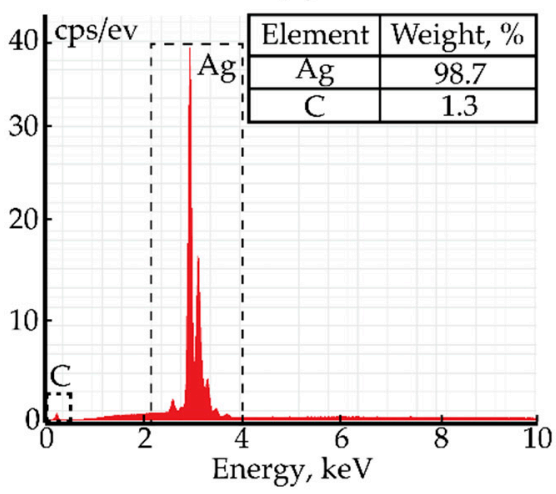

(g)

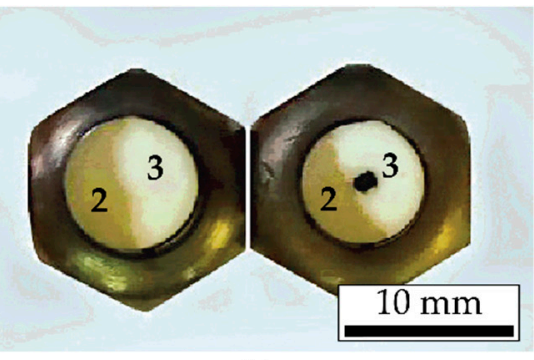

(b)

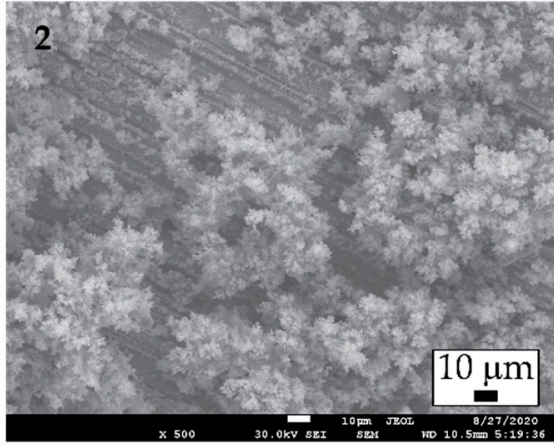

(e)

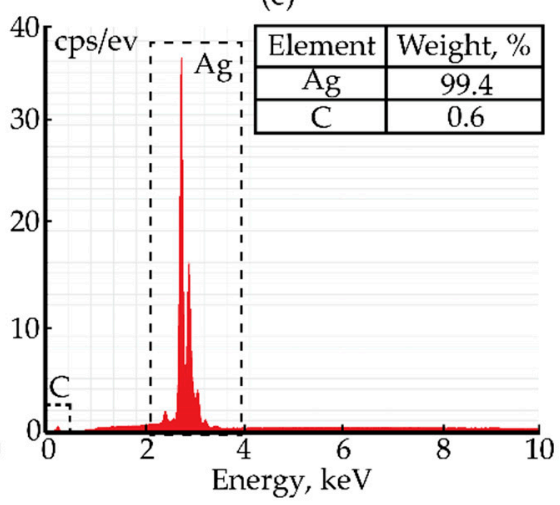

(h)

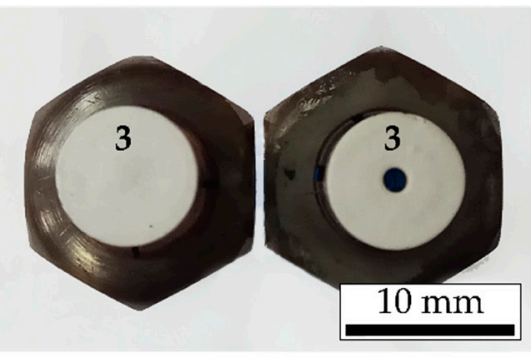

(c)

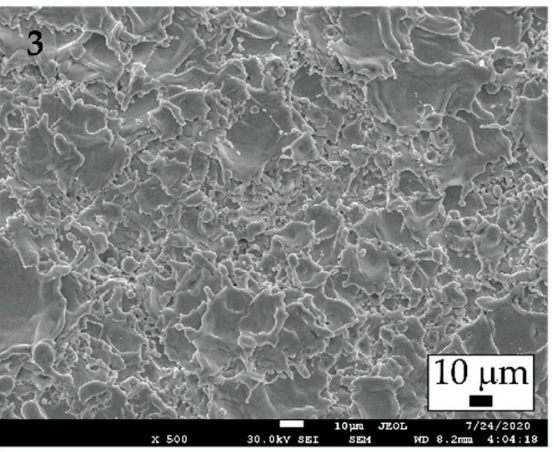

(f)

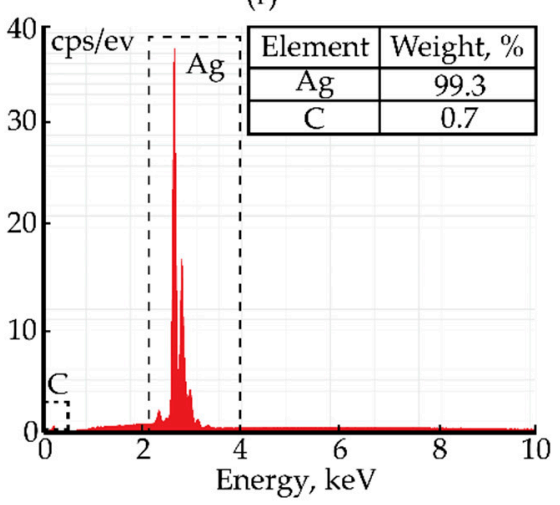

(i)

Figure 4. (a) Photos of the polished electrodes, (b) the electrodes after $6 \mathrm{~h}$ of NP synthesis with the ends initially located at the angle of $15^{\circ}$ and (c) with the initially parallel ends, (d-f) SEM images of the corresponding characteristic areas 1, 2, 3, indicated in the photos of the electrode ends, and (g-i) EDX spectra of Ag electrode surfaces marked 1-3 in (a-c).

For the three cases of the mutual arrangement of electrodes end faces (in parallel and at the angles of $7^{\circ}$ and $15^{\circ}$ ), time dependences of modal distribution sizes of NP agglomerates and their concentrations, determined by electrical mobility during $6 \mathrm{~h}$ of NP synthesis, were studied (Figure 5).

A characteristic of the measured dependences of agglomerates' modal dimensions from time is their asymptotic approximation to the average size of about $150 \mathrm{~nm}$ during $6 \mathrm{~h}$ of NP synthesis for each of the three cases of mutual arrangement of electrodes' end faces. Such an asymptotic behavior of the average agglomerate size-time-function indicates the stability of the SD process on asymmetrically installed electrodes, which leads to the formation of parallel end faces. The dependences comparison for the three cases shows that the average initial agglomerates' size and the average curvature of the function are higher with a greater degree of the electrodes' asymmetry. These features can be explained by a higher wear rate of electrodes with the end faces located at a large angle, due to their electrical erosion. 


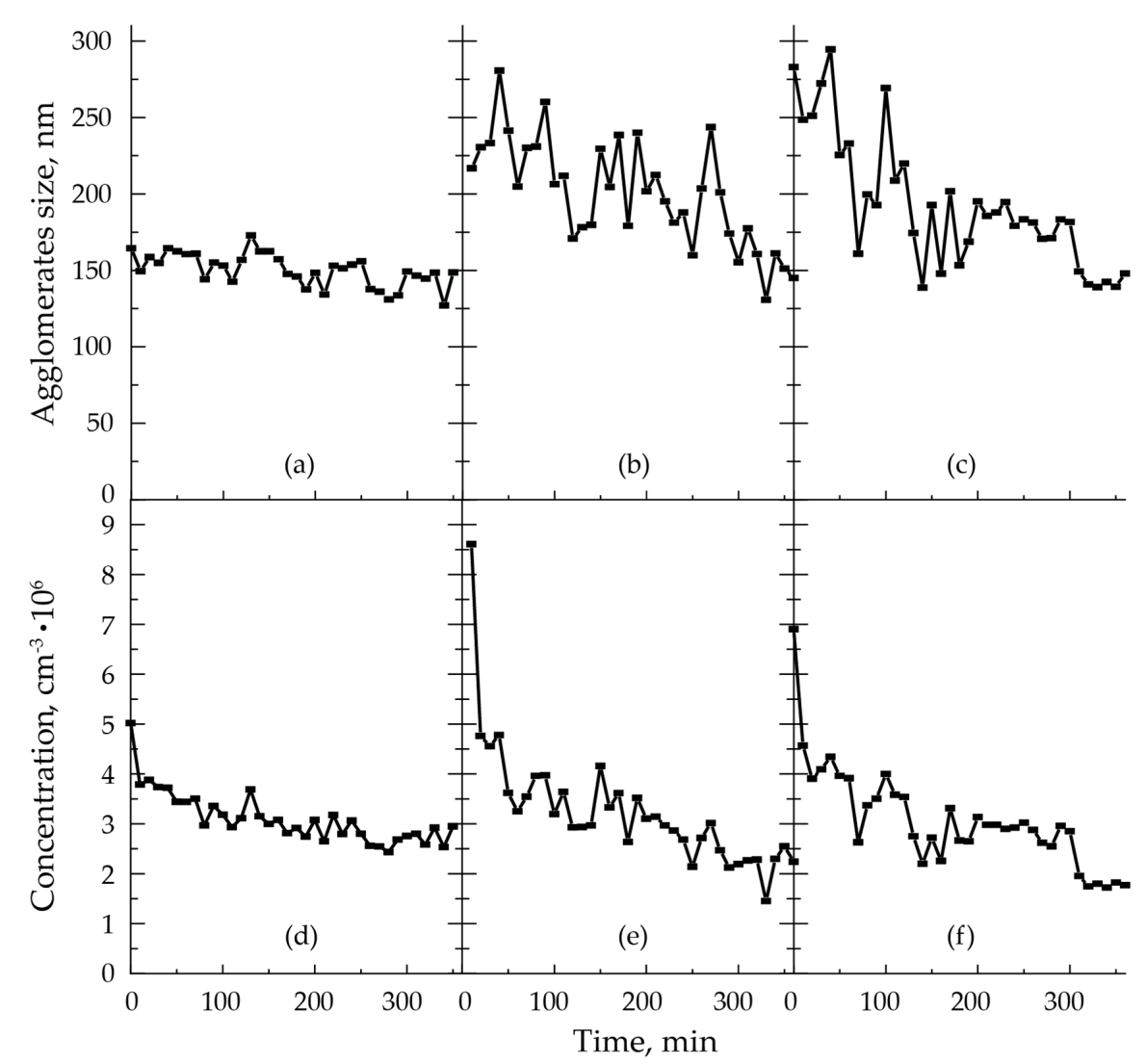

Figure 5. Time dependences of the modal size of NP agglomerates and their concentrations during the electrodes wear by the ODP for electrodes with ends $(\mathbf{a}, \mathbf{d})$ located parallel and at the angles of $(\mathbf{b}, \mathbf{e}) 7^{\circ}$ and $(\mathbf{c}, \mathbf{f}) 15^{\circ}$.

The behavior of the dependences of the capacitor charging voltage and frequency of capacitor discharges with the ODP for the three cases of the electrodes' end arrangement, as it can be seen from Figure 6, has a common feature after the start of charge-discharge processes. Within first $5 \mathrm{~min}$, there is an almost-identical decrease in the capacitor charging voltage and a simultaneous increase in the discharge frequency by about $35 \%$. This effect is logically associated with the establishment of a stationary high-temperature regime in the spark gap and in electrodes. Next, the charging voltage curves monotonically increase and the discharge repetition rate curves monotonically decrease faster as the initial angle between electrodes' end faces increases. This effect can be associated with the erosion wear of the beveled electrodes end faces and, consequently, with a more rapid increase in the interelectrode gap distance in comparison with the case of parallel setup of the electrodes' ends. This behavior correlates well with increased modal size of NP agglomerates and their concentrations with an increase in the angle between electrodes' ends (Figure 5). We also note that the configuration of the electrodes' arrangement with the parallel ends gives the most stable behavior of the dependences of the capacitor charging voltage, frequency of discharges, and modal size of synthesized NP agglomerates and their concentrations.

It is also of interest to compare characteristic dimensions of craters formed by the SD on surfaces of electrodes initially installed parallel and at the angle $15^{\circ}$ (Figure 7a,b). SEM images of the electrode surfaces being under erosion for $2 \mathrm{~h}$ were analyzed. The analysis was carried out only for the upper craters with a closed outer border in the form of a breastwork. As it can be seen from the comparison of the crater size distributions (Figure 7c,d), in the case of the initial parallel arrangement of electrodes end faces, the size of craters is noticeably smaller than when the electrodes end faces are located at an angle. This effect is logically explained by a smaller equivalent working area of electrodes' initially installed at an angle, and, as a result, a higher average discharge current density. At the 
same time, the craters' average diameter is less than $20 \mu \mathrm{m}$ in both cases, corresponding to experimental observations in previously performed works of other authors [34-36].

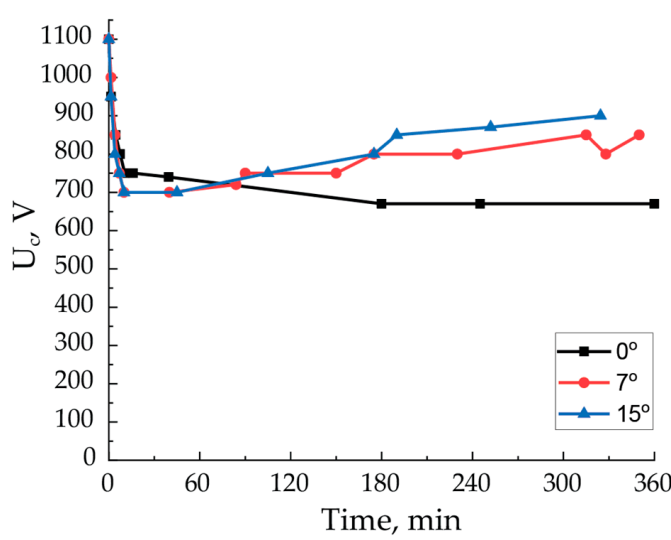

(a)

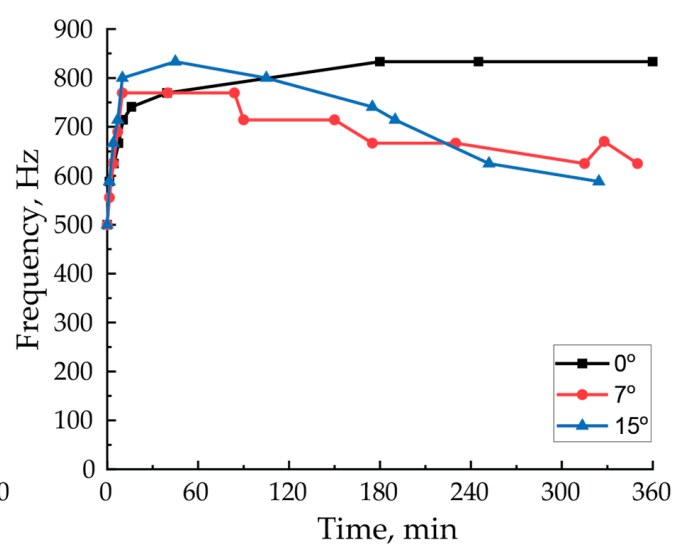

(b)

Figure 6. The dependences of (a) the capacitor charging voltage and (b) frequency of the capacitor discharges for the case of synthesis with the ODP for electrodes' ends located parallel and at angles of $7^{\circ}$ and $15^{\circ}$.

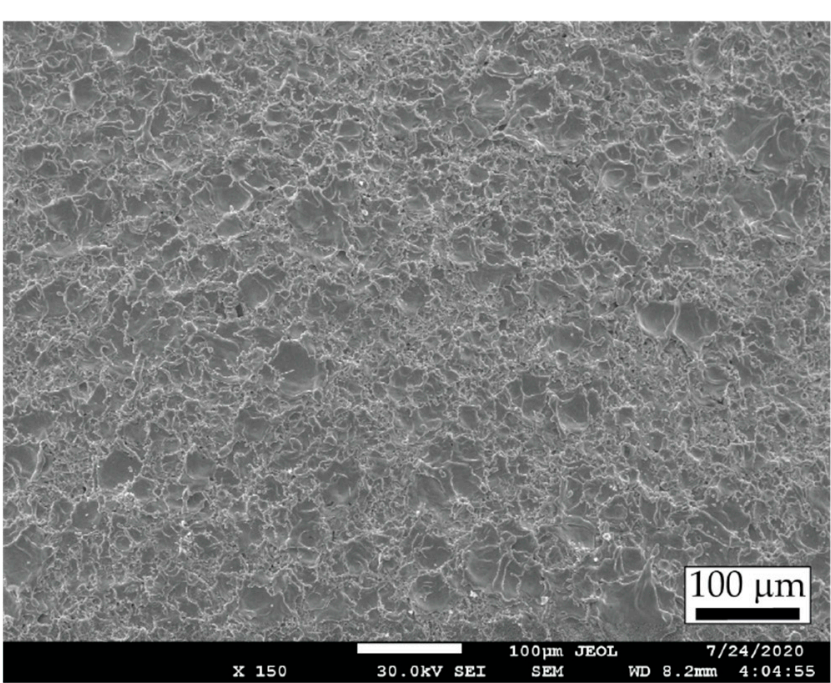

(a)

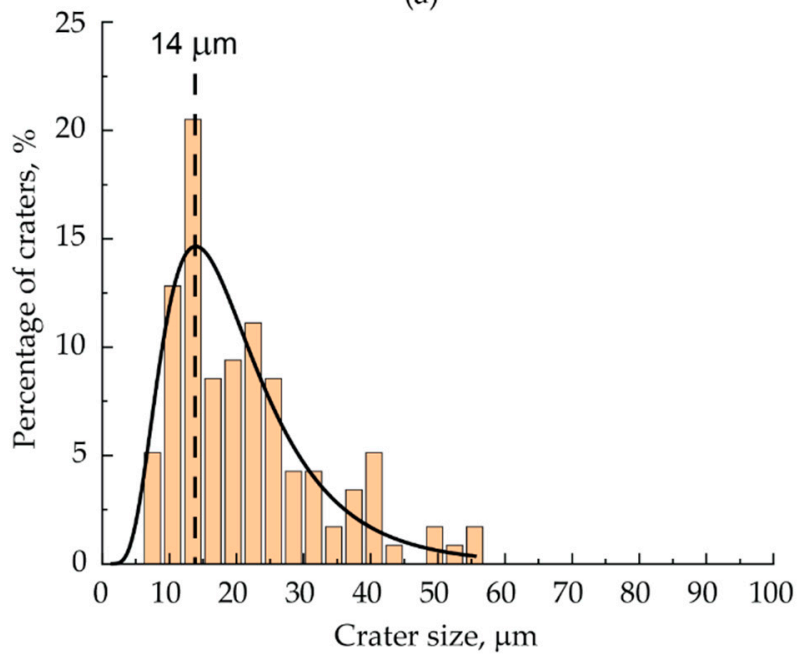

(c)

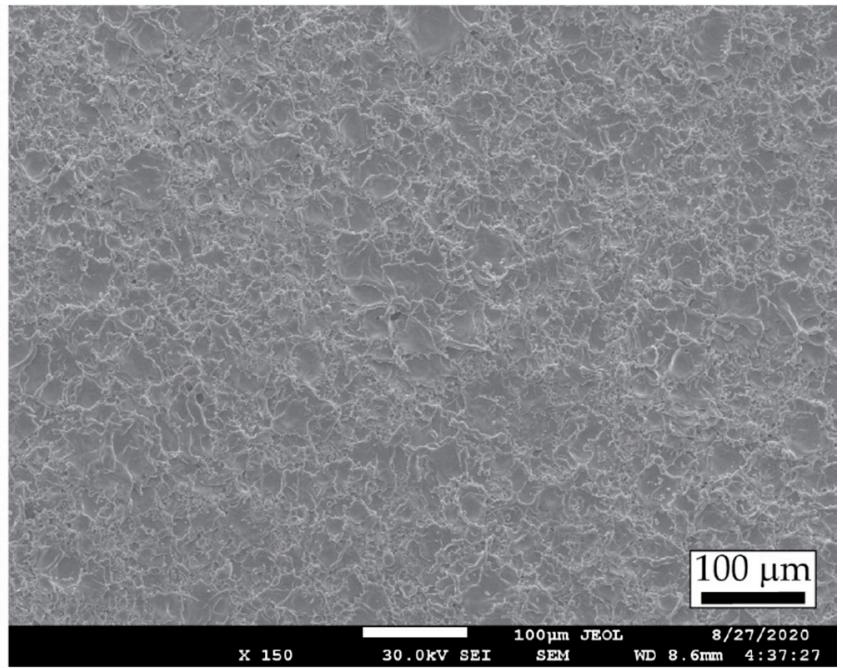

(b)

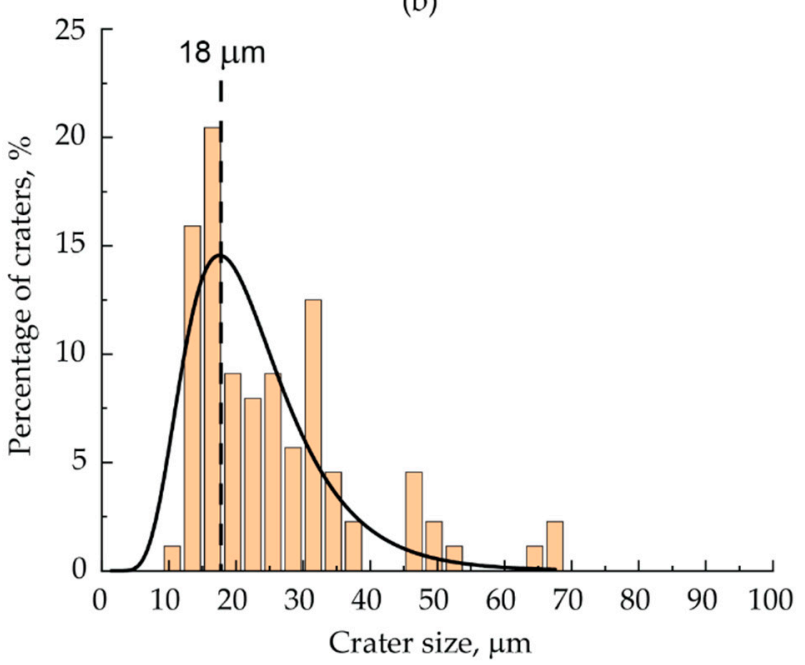

(d)

Figure 7. (a,b) SEM images of electrode faces subjected to electrical erosion and (c,d) the size distributions of craters for the cases of $(\mathbf{a}, \mathbf{c})$ the initial parallel arrangement of ends and $(\mathbf{b}, \mathbf{d})$ at the angle of $15^{\circ}$. 
The sizes of synthesized primary NPs collected on TEM grids were analyzed on a series of TEM images (Figure 8a-c) for the three cases of the initial arrangement of electrodes end faces: parallel and at the angles of $7^{\circ}$ and $15^{\circ}$. For this purpose, we obtained number-size distributions of NPs as part of agglomerates, and next converted them into mass-size distributions (Figure 8e,f), which clearly reflect the mass fraction of particles of different sizes.

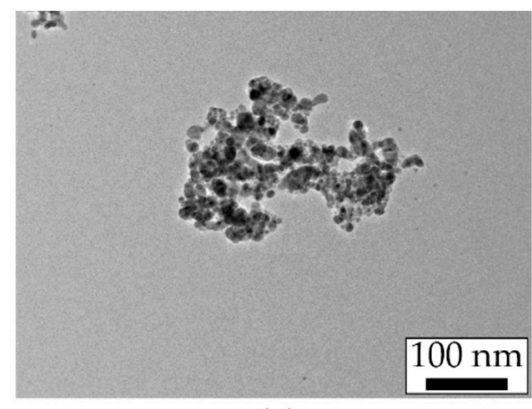

(a)

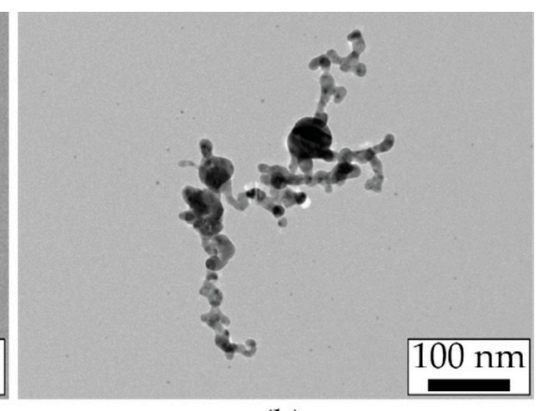

(b)

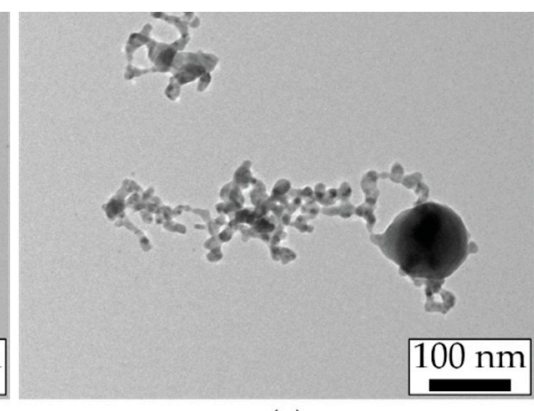

(c)

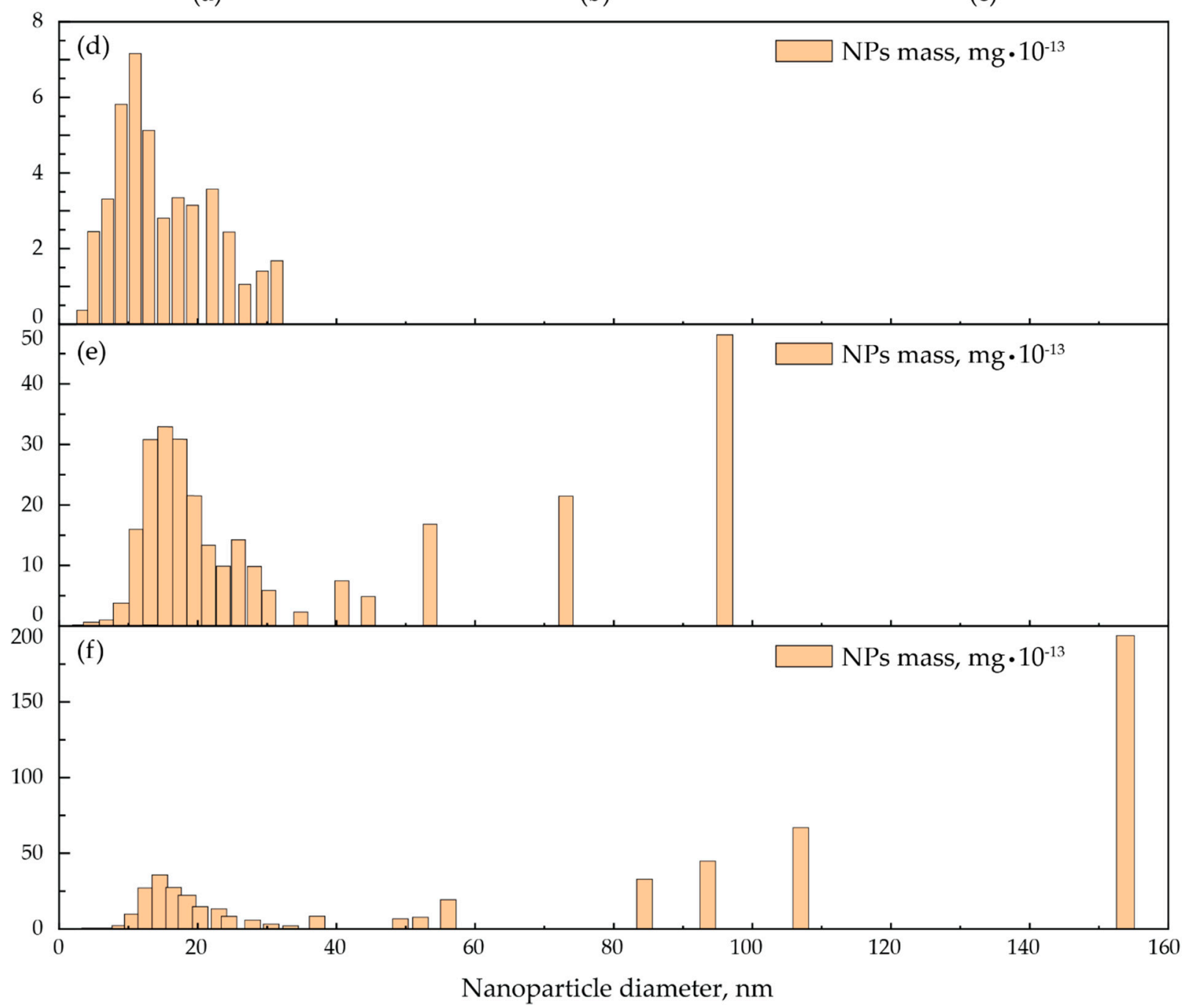

Figure 8. (a-c) TEM images and (d-f) mass distributions of NPs for the synthesis with the ODP and electrodes ends arranged $(\mathbf{a}, \mathbf{d})$ parallel and at the angles of $(\mathbf{b}, \mathbf{e}) 7^{\circ}$ and $(\mathbf{c}, \mathbf{f}) 15^{\circ}$.

The given mass distributions qualitatively and quantitatively characterize the size and shape of synthesized NPs and their agglomerates for the three variants of the electrode ends arrangement. When going from the case of the parallel end faces arrangement to the 
case of their setup at a large angle, the NPs agglomeration increases, individual NPs form necks and NP agglomerates transform into aggregates. Additionally, despite the increase in the proportion of particles with a diameter up to $40 \mathrm{~nm}$, the number of large parasitic particles with a size larger than $40 \mathrm{~nm}$ increases with an increase in the asymmetry degree of the electrodes' arrangement (Figure 8f). The mass fraction of parasitic particles turns out to be significant and equals $33 \%$ and $66 \%$ for the location of electrodes' ends at the angles of $7^{\circ}$ and $15^{\circ}$, respectively.

When calculating the energy efficiency of the SDG, it was taken into account that the capacitor charging voltage $U_{c}(t)$ and the discharge frequency $v(t)$ are the values changing over the time of NP synthesis (Figure 7). Therefore, the total energy periodically stored in the capacitor and transferred to the discharge circuit during the NP synthesis operation time $t$ was determined by the next formula [33]:

$$
E_{t}=\int_{0}^{t} \frac{C U_{c}^{2}(t)}{2} v(t) d t .
$$

To determine the part of the energy released directly in the spark gap, one can use the equivalent representation of the spark gap by the constant electrical resistance $R_{s}$. In this case, the total energy released per single discharge pulse of length $\tau$ can be represented as a sum of two terms: the energy release in elements of the discharge circuit and the energy release in the spark gap:

$$
E_{\text {pulse }}=R \int_{0}^{\tau} I^{2} d t+R_{s} \int_{0}^{\tau} I^{2} d t .
$$

A similar approach of calculating the discharge energy parameters was previously used in the works [1,26]. Using Formula (3), total energy released in the interelectrode gap during the whole SD process is calculated as follows:

$$
E_{t}^{s}=E_{t} \frac{R_{s}}{R_{e}} .
$$

The energy efficiency characterizing the useful output of the SDG is the synthesized NPs mass produced per unit useful energy consumed and expressed by the formula [1]:

$$
m_{e}^{d}=\frac{\Delta M}{E_{t}^{s}},
$$

where $\Delta M=\Delta M_{1}+\Delta M_{2}$ is the total mass of the synthesized NPs, equal to the mass loss of the two electrodes as a result of the NPs synthesis for time $t$. The total NPs mass after $6 \mathrm{~h}$ of synthesis, and the corresponding energy efficiency for the ODP at different arrangements of electrodes' end faces are presented in Table 1.

Table 1. The decrease in the electrodes' mass, the energy release in the interelectrode gap, and the energy efficiency of synthesis with the ODP.

\begin{tabular}{cccccc}
\hline Angle $^{\circ}$ & $\boldsymbol{\Delta} \boldsymbol{M}_{\mathbf{1}}, \mathbf{m g}$ & $\boldsymbol{\Delta} \boldsymbol{M}_{\mathbf{2}}, \mathbf{m g}$ & $\boldsymbol{\Delta} \boldsymbol{M}, \mathbf{m g}$ & $\boldsymbol{E}_{\boldsymbol{t}}^{\boldsymbol{s}}, \mathbf{k J}$ & $\boldsymbol{m}_{\boldsymbol{e}}^{\boldsymbol{s}}, \frac{\boldsymbol{\mu g}}{\mathrm{kJ}}$ \\
\hline 0 & $12.90 \pm 0.01$ & $21.87 \pm 0.01$ & $34.77 \pm 0.01$ & $304 \pm 3$ & $114 \pm 1$ \\
\hline 7 & $24.29 \pm 0.01$ & $47.34 \pm 0.01$ & $71.63 \pm 0.01$ & $316 \pm 3$ & $226 \pm 2$ \\
\hline 15 & $30.12 \pm 0.01$ & $47.28 \pm 0.01$ & $77.40 \pm 0.01$ & $323 \pm 3$ & $239 \pm 2$ \\
\hline
\end{tabular}

The maximum mass consumption of electrodes was observed for the ends installed at angles of $7^{\circ}$ and $15^{\circ}$. This feature can be explained by comparison of the actual mass consumption of the electrodes after $6 \mathrm{~h}$ of NP synthesis with the NP mass-size distribution (Figure 8). Additionally, with an increase in the angle between electrodes' end faces, an increase in the energy efficiency of the NP synthesis is evident. 


\subsection{The Influence of the Degree of Electrodes Asymmetry on the NP Synthesis with the UDP}

The UDP, which occurs when the ballast resistor is inserted in the discharge circuit, was characterized by approximately twice less amplitude and duration comparable to one half-wave of the ODP. Thus, the total electric charge passing through the spark gap in a single discharge pulse was about 7 times less for the UDP than for the ODP. For this reason, the electrical erosion wear of the electrodes during the several hours of the experiment was not sufficient to form on the cathode a significant area parallel to the anode, even at the angle of $10^{\circ}$. Therefore, experiments on the electrical erosion of electrodes and NP synthesis by the UDP were carried out with unchanged electrode shape at the macroscale.

It was found that, in processes of NP synthesis with the UDP, in cases of parallel arrangement of electrodes' ends or with a small slope of the cathode surface $\left(3^{\circ}\right)$, an electroerosive instability of the spark process occurred. It was manifested in the localization of spark channels to some response areas of electrodes end faces and was random in time. On the anode end face, a protrusion from the electrodes material had been appearing at the location of the spark channel. The protrusion grew over time and reduced the gap between electrodes. Reaching the cathode, it formed a metal bridge between electrodes, short-circuiting the interelectrode gap and ceasing spark discharges and NP synthesis. The start of the protrusion's rapid growth from the anode to the cathode is clearly indicated by the sudden change in functions of the capacitor charging voltage and the frequency of the capacitor discharges. This is represented in Figure 9 by black and red lines. The time of the beginning of the metal protrusion formation on the anode is longer for the cathode end face orientation at the angle of $3^{\circ}$ than for the case of parallel arrangement of electrodes' ends. In the case of the cathode end face oriented at an angle, NP deposition on the anode reduces as it becomes easier for NPs to leave the interelectrode gap. Obviously, the protrusion is formed by NPs synthesized from the cathode material and transferred to the anode.

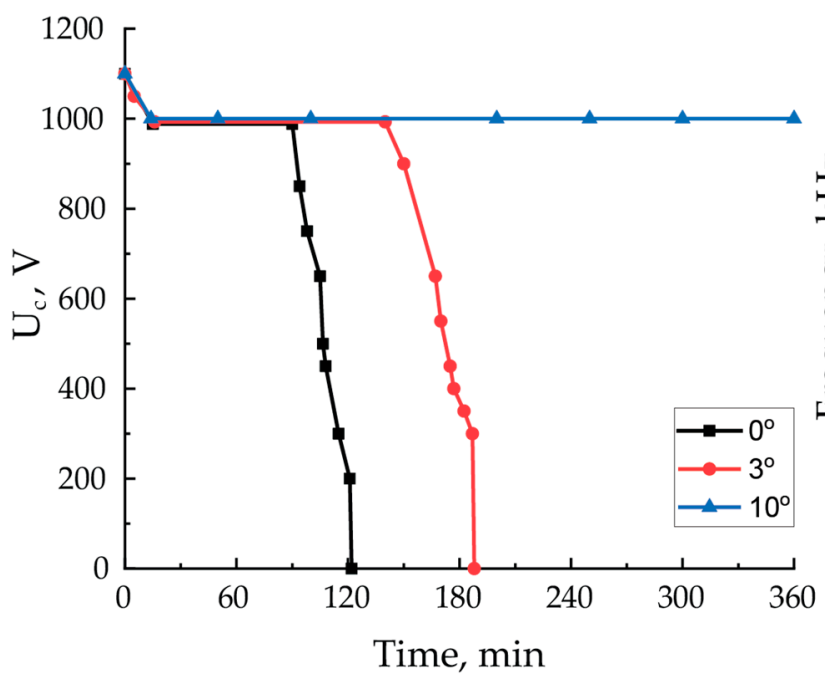

(a)

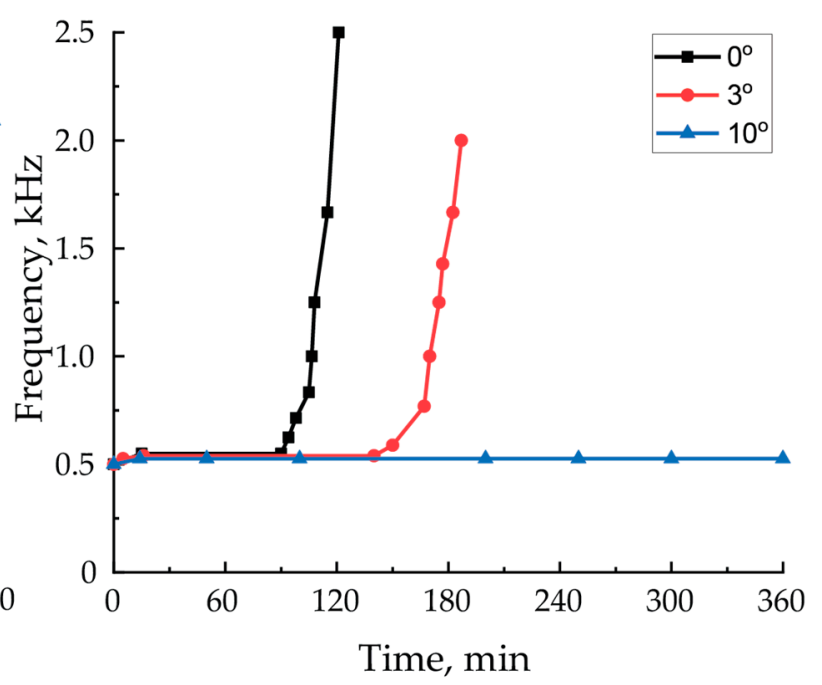

(b)

Figure 9. The dependences of (a) the capacitor charging voltage and (b) the frequency of capacitor discharges for the case of synthesis with the UDP for electrodes' ends arranged in parallel and at the angles of $3^{\circ}$ and $10^{\circ}$.

The time dependences of modal sizes and concentrations of NP agglomerates synthesized in the SD with the UDP at different arrangements of the electrode ends are shown in Figure 10. From the comparison of these dependences, one can see an increase in the initial modal size of agglomerates with an increase in the angle between electrodes' end faces. This can be explained in the analogy with the case of the ODP by the localization of SDs in the area of the shortest distance between electrodes that leads to the increased current density in the SD and to the synthesis of large NPs. 


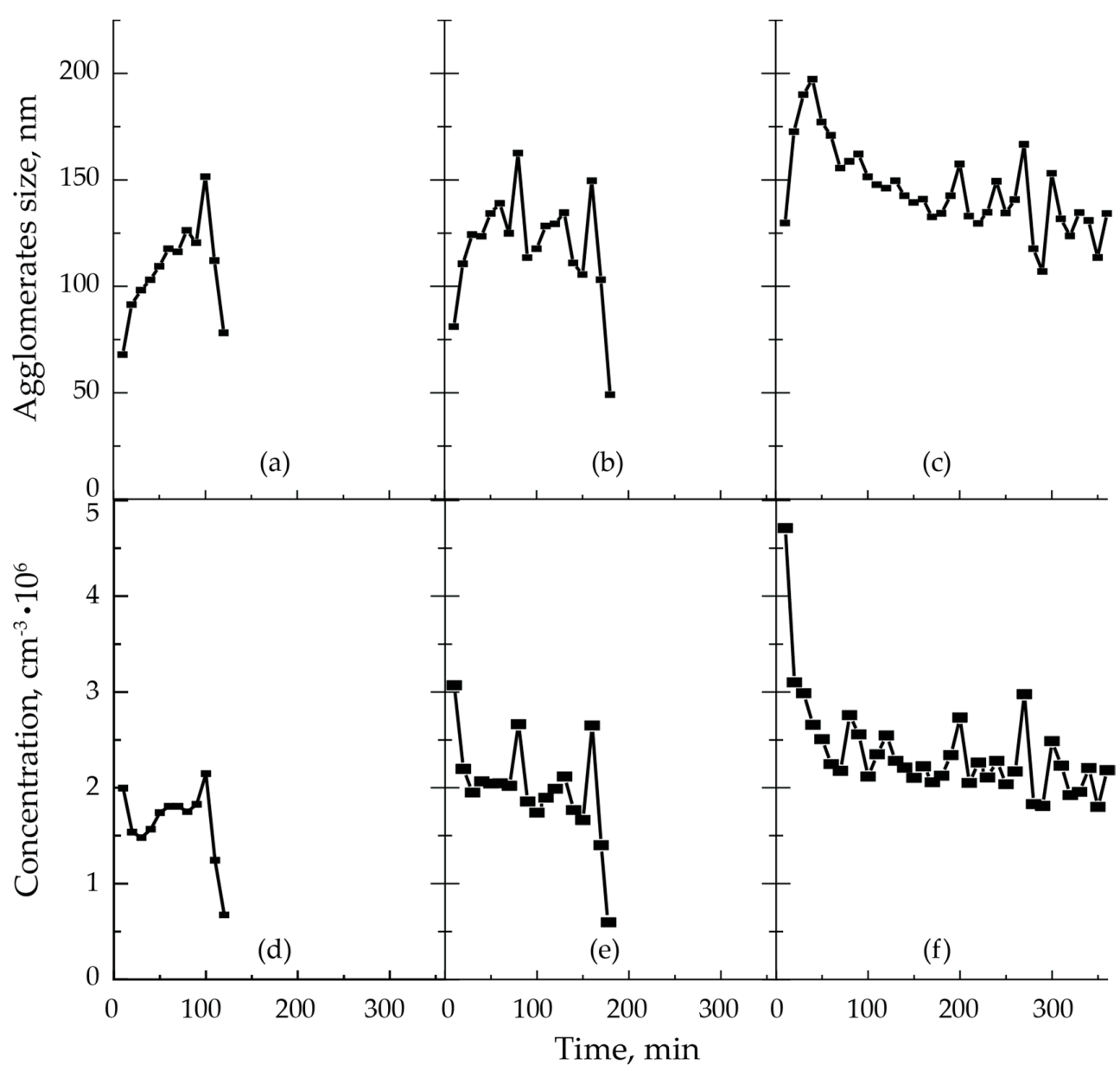

Figure 10. Time dependences of the modal size of NP agglomerates and their concentrations during the electrodes wear by the UDP for electrodes ends arranged $(\mathbf{a}, \mathbf{d})$ in parallel and at the angles of $(\mathbf{b}, \mathbf{e}) 3^{\circ}$ and $(\mathbf{c}, \mathbf{f}) 10^{\circ}$.

Since, in the case of the UDP, a significant part of the capacitor's energy was dissipated on the ballast resistor, the energy spent on the electrical erosion of the electrode material was much lower than in the case of the ODP, and the synthesized NP agglomerates had smaller dimensions. Herewith, for the arrangement of electrodes ends at the maximum angle $\left(10^{\circ}\right)$, an asymptotic approximation of the dependence of modal sizes of NP agglomerates from time to the average size of about $130 \mathrm{~nm}$ is observed.

In the process of NP synthesis with the UDP, the anode end face is covering with an array of dendrite-like NPs. The cathode end face is modified by electrical erosion, followed by the formation of a set of overlapping microcraters. Such microcraters are formed as a result of evaporation and spilling of metal heated by the SD at places where it occurs on the cathode. According to the SEM images of electrode ends shown in Figure 11, one can observe the structure of their typical surface after the prolonged treatment by SDs. Since craters are found only on the cathode, we can logically assume that the anode is covered with NPs synthesized on the cathode. Thus, NPs synthesized from the cathode material are partially transferred to the anode and partially carried away in the form of aerosol by the transport gas. Herewith, the average size of craters turns out to be much smaller for the UDP than for the ODP (Figure 7c,d and Figure 11c,d). Moreover, the average crater's dimensions were found to be larger at the area of spark channel location on the cathode (Figure 11c) opposite the growing protrusion on the anode than at the cathode area aside the spark channel location (Figure 11d). 


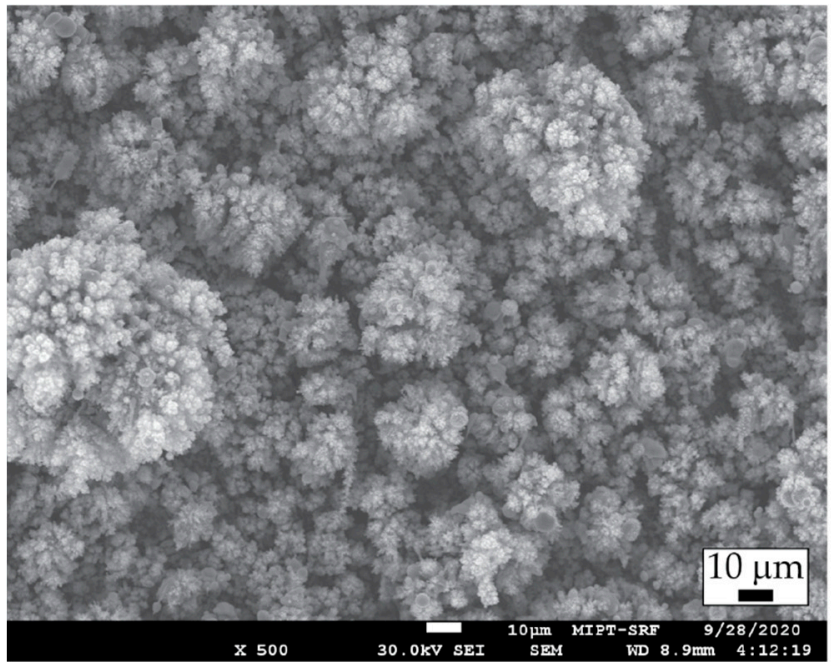

(a)

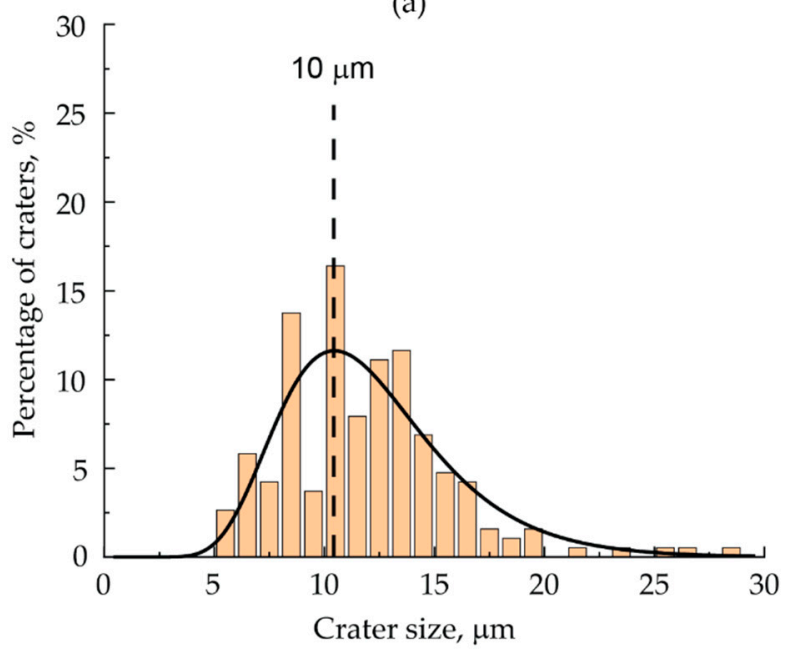

(c)

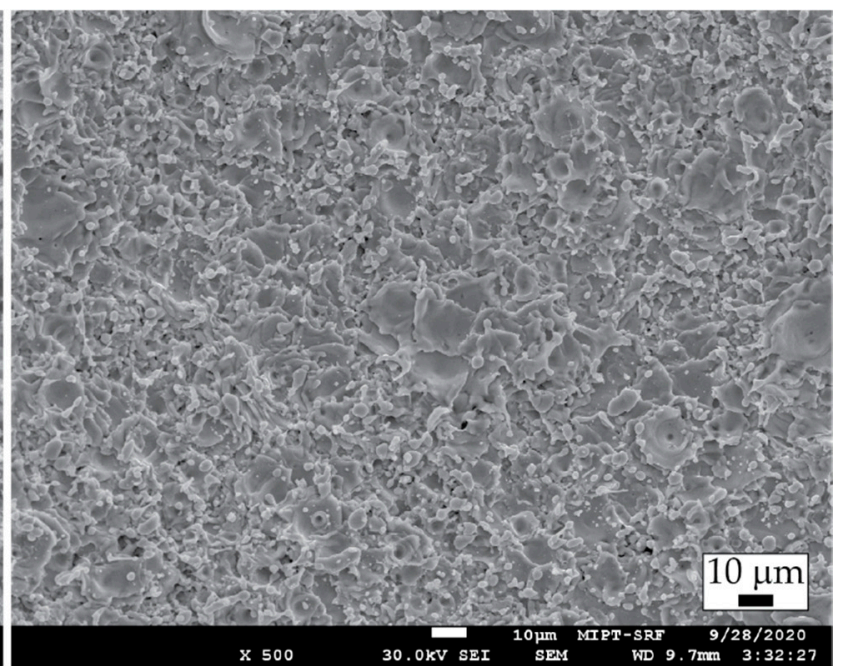

(b)

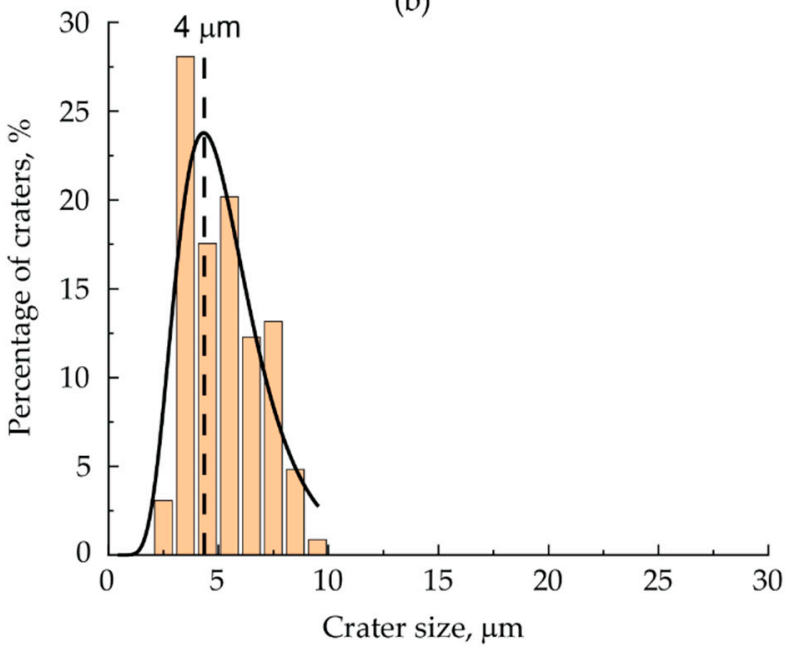

(d)

Figure 11. SEM images of typical surfaces of the (a) anode and (b) cathode after prolonged processing in the SD with the UDP and size distributions of craters on the cathode (c) at the area of spark channel location opposite the growing protrusion on the anode and (d) at the area aside the spark channel location for the case of the initial parallel arrangement of electrodes' ends.

A protrusion formed on the anode with the UDP was studied in optical and scanning electron microscopes (Figure 12). The photo in Figure 12a shows the localization of the spark channel in the discharge process at the stage of growth of the protrusion from the upper electrode (anode). Moreover, before the main protrusion growth begins, many clusters of NPs are gather on the anode in the form of micro-protrusions, which are located in a ring at a distance of about $2 \mathrm{~mm}$ from the center of the anode (in Figure 12b inside the dashed circle). When one of those protrusions begins to dominate, the growth of remaining protrusions stops, except for a single one quickly moving to the cathode, closing the interelectrode gap with a conducting bridge. Localization of the SD channel from a growing protrusion is similar to the previously observed SD processes with the pin-to-plane electrode configuration for pin-cathode [37] and pin-anode cases [38]. 


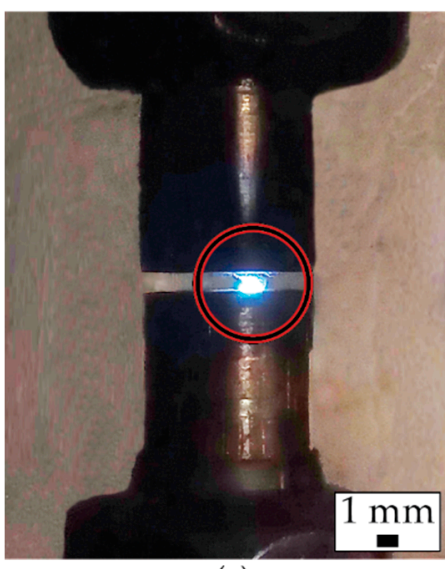

(a)

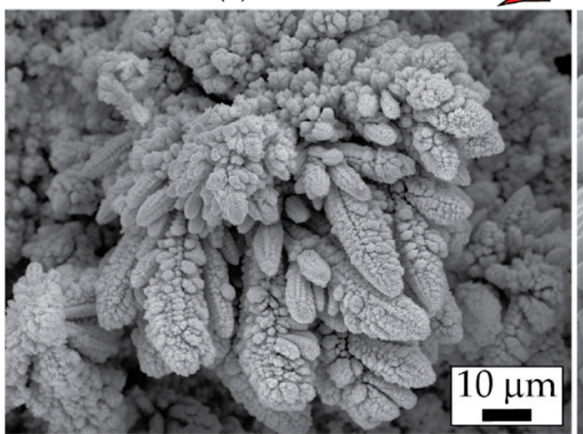

(d)

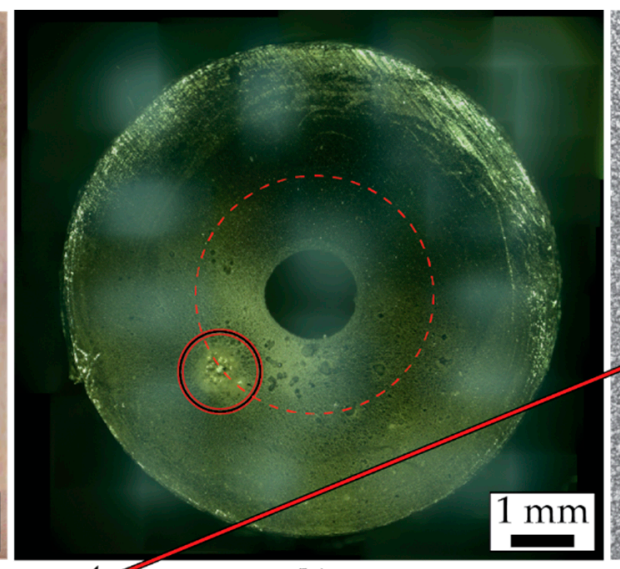

(b)

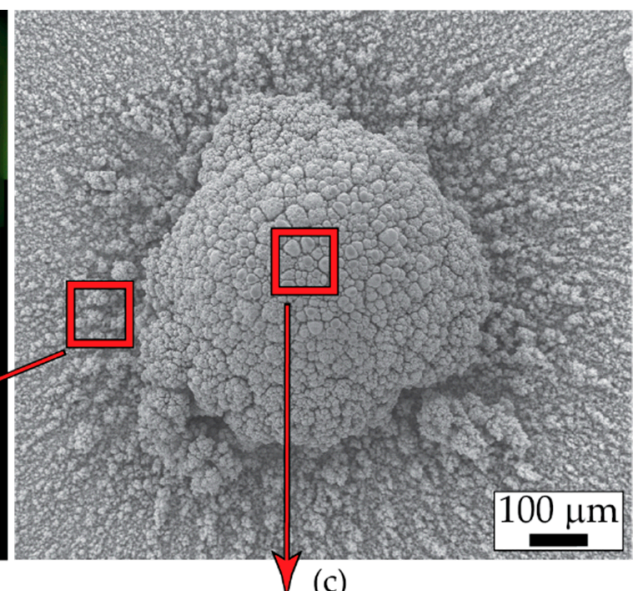

(c)

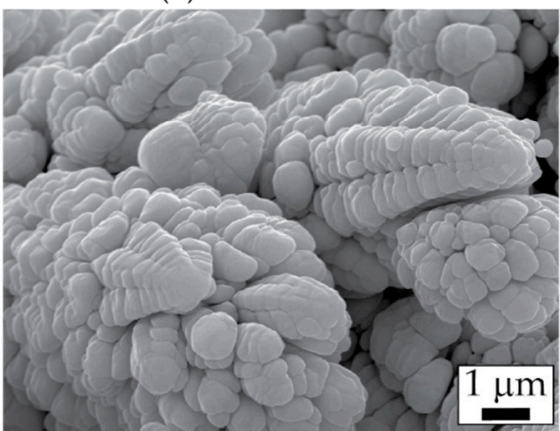

(e)

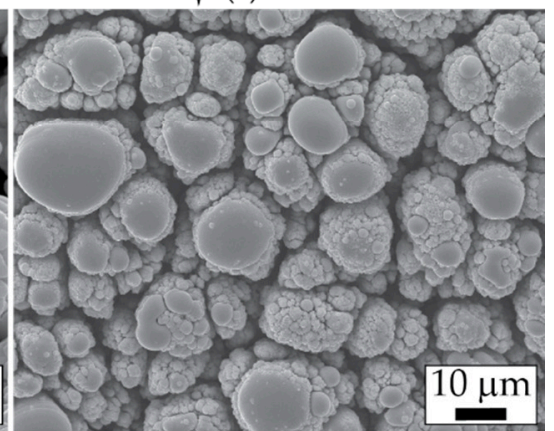

(f)

Figure 12. (a) Photo of the SD localization in the spark gap at the point of growth of the protrusion from the anode; (b) Optical microscope image of the anode end face with the designation of micro-protrusions formation area (dashed circle) and the dominant protrusion (solid circle); (c-f) SEM images of characteristic parts of the growing protrusion microstructure. Subfigure (e) is a magnified part of subfigure $(\mathbf{d})$.

The microstructure study of the growing conductive protrusion (Figure 12c) in SEM allows us to conclude that in the central part of the protrusion the stacking of dendritelike NP agglomerates is dense (Figure 12f) and on its periphery, the NP agglomerates assemble in the form of clusters with a loose stacking (Figure 12d,e). At the same time, many dendrite-like agglomerates in the central part of the protrusion are molten, probably due to their participation in the transfer of the SD current to the anode (Figure 12f).

In experiments with the UDP, we analyzed the dispersed composition of aerosol NPs by TEM and measured the mass loss of the cathode and anode. According to a series of TEM images of NPs (for example, Figure 13a-c) for each of the three variants of the electrodes' ends arrangement, the mass-size distributions of NPs (Figure 13d-f) were determined. It indicates that with an increase in the degree of electrodes asymmetry the NP agglomeration increases. In the case of electrodes parallel ends, a large number of isolated NPs were observed (Figure 13a). In the case of the electrodes' ends arrangement at the angle of $3^{\circ}$, the particles mainly formed small agglomerates. At the angle between ends of $10^{\circ}$, the energy release density in the discharge became sufficient for the fusion of NPs with the necks' formation specific for strong aggregation. At the same time, in all cases, a great number of NPs with sizes of 2-5 nm were observed, which did not make a significant contribution to the mass distribution. However, we have not detected NPs larger than $40 \mathrm{~nm}$ in these experiments, probably due to an order of magnitude lower energy release in the spark gap compared to similar experiments with the ODP. 


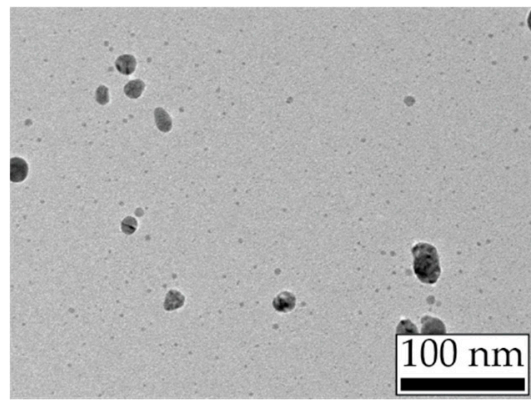

(a)

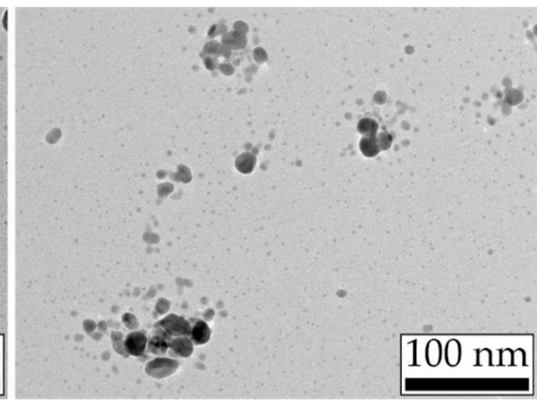

(b)

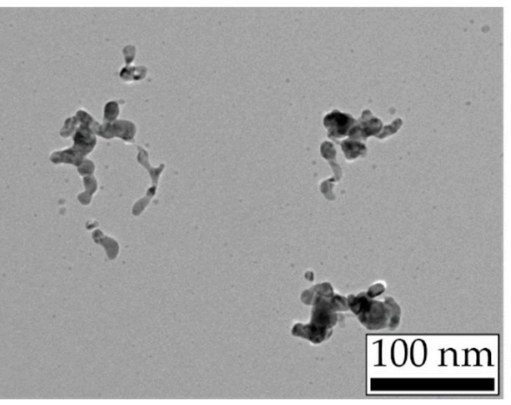

(c)

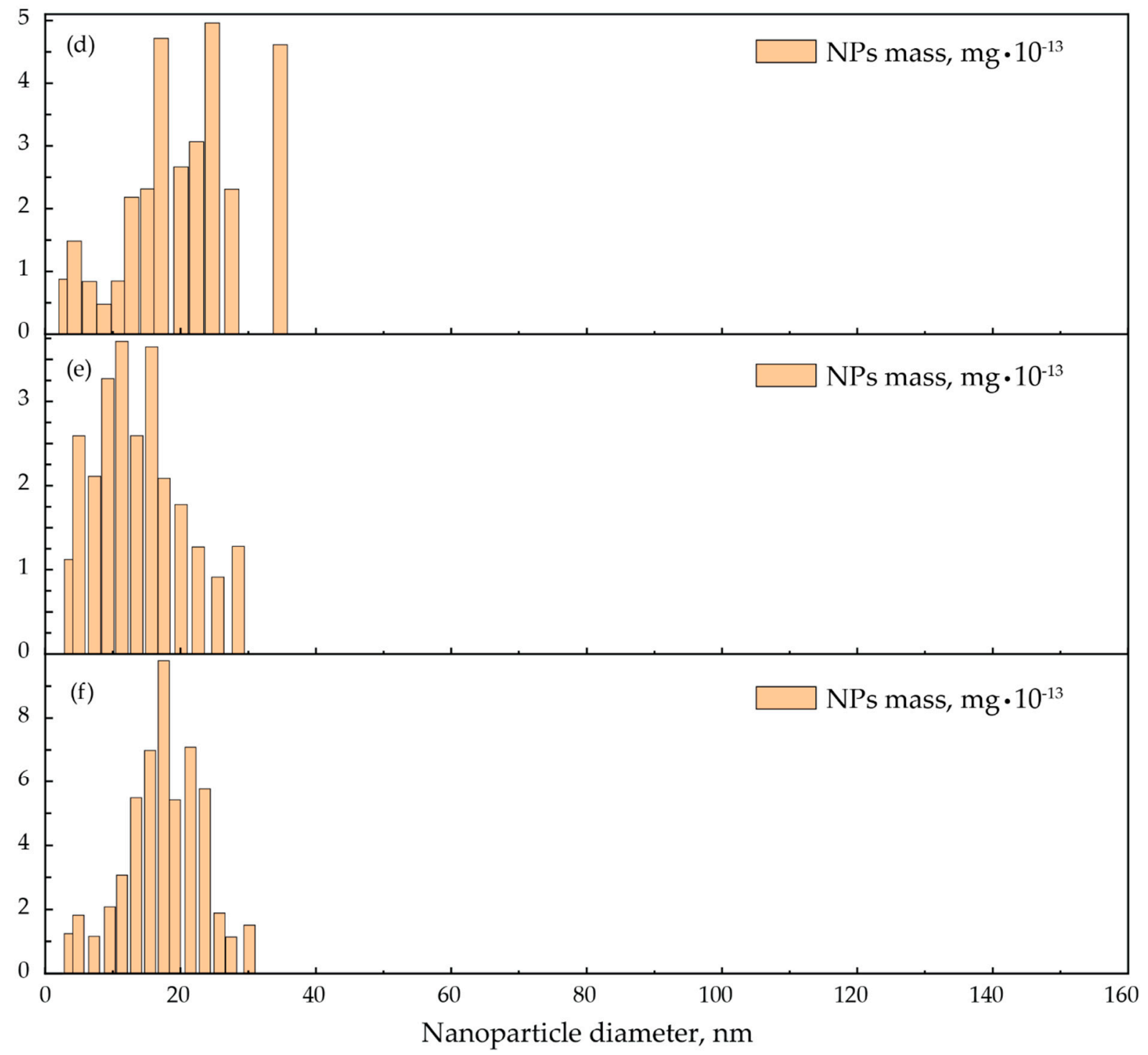

Figure 13. (a-c) TEM images and (d-f) mass-size NPs distributions for the cases of NP synthesis with the UDP for electrodes' end faces arranged $(\mathbf{a}, \mathbf{d})$ in parallel and at angles $(\mathbf{b}, \mathbf{e}) 3^{\circ}$ and $(\mathbf{c}, \mathbf{f}) 10^{\circ}$.

Analysis of changes in the electrodes' mass after the completion of the SD process with the UDP showed that the main mass loss was at the cathode, and the anode mass might even slightly increase (Table 2). The increase in mass is logically associated with the transfer of synthesized NPs to the anode, including the growth of a metal protrusion leading to the formation of an interelectrode bridge. From Table 2, one can see that the electrodes' mass loss (mainly for the cathode) grows with an increase in the degree of 
electrode asymmetry. However, the energy efficiency in the case of the UDP varies slightly depending on the angle between electrodes' ends.

Table 2. The electrodes' mass loss, the energy release in the interelectrode gap, and the energy efficiency of the NP synthesis with the UDP.

\begin{tabular}{|c|c|c|c|c|c|}
\hline Angle, ${ }^{\circ}$ & $\Delta M_{\text {anode }}, \mathrm{mg}$ & $\Delta M_{\text {cathode, }} \mathrm{mg}$ & $\Delta M, \mathrm{mg}$ & $E_{t}^{d}, \mathrm{~kJ}$ & $m_{e}^{d}, \frac{\mu \mathrm{g}}{\mathrm{kJ}}$ \\
\hline 0 & $-0.68 \pm 0.01$ & $3.41 \pm 0.01$ & $2.73 \pm 0.01$ & $18.0 \pm 0.2$ & $152 \pm 2$ \\
\hline 3 & $0.33 \pm 0.01$ & $5.01 \pm 0.01$ & $5.34 \pm 0.01$ & $28.7 \pm 0.3$ & $186 \pm 2$ \\
\hline 10 & $-0.14 \pm 0.01$ & $7.72 \pm 0.01$ & $7.58 \pm 0.01$ & $60.9 \pm 0.6$ & $124 \pm 1$ \\
\hline
\end{tabular}

\section{Discussion}

As established in the experiments presented above with the pulse-periodic SD, in the regimes with the ODP and the electrodes' asymmetric arrangement during the NP synthesis, their protruding parts are increasingly worn out by electrical erosion, forming parallel surfaces that increase in area and are covered with craters from spot discharges. At each moment of time, a certain area of the electrode is involved in electric discharge processes, usually in the form of a segment of the electrode cross-section (for example, in Figure $4 \mathrm{~b}$ ). Thus, we can say that from the start of the pulse-periodic SD process, equivalent working areas of electrodes, in the case of their ends arranged at an angle, increase from a minor value to the full cross-sectional area of the electrode perpendicular to its axis.

The kinetics of the increase in the working area of the electrodes arranged at an angle is correctly displayed by the observed patterns of decreasing time dependencies of the average NP agglomerate size and their concentration measured in the flow by NP electrical mobility (Figure 5). Additionally, the role of the small working area of electrodes initially arranged at an angle is in the greater average energy efficiency $m_{e}^{s}$ over $6 \mathrm{~h}$ of the process for higher angles between electrodes end faces (Table 1). The average energy efficiency is the integral with respect to time from current energy efficiency function, monotonically decreasing from the start highest value. Experimental data obtained allow us to estimate the decrease in kinetics of the current energy efficiency and its maximum initial value. The current energy efficiency

$$
m_{e}(t)=\mu(t) / P_{d}(t)
$$

is followed from (5) and expressed as the mass loss rate by synthesized NPs $\mu(t)$ per current power released in the interelectrode gap determined from (2) and (4):

$$
P_{d}(t)=\frac{R_{s}}{R_{e}} \frac{C U_{c}^{2}(t)}{2} v(t) .
$$

The mass loss rate by synthesized NPs $\mu(t)$ can be estimated from experimental dependencies of the concentration $N(t)$, the average size of NP agglomerates $D(t)$, measured by their electrical mobility (Figure 5), and from the value of the electrode mass loss $\Delta M$ (Table 1) [39]:

$$
\mu(t)=\frac{d M}{d t}=A \frac{\pi}{6} D^{3}(t) \rho N(t) V=\Delta M \frac{N(t) D^{3}(t)}{\int_{0}^{T} N(t) D^{3}(t) d t},
$$

where $\rho$ is the density of the NP material, $V$ is the gas flow through the synthesis chamber and $A$ is the constant coefficient that takes into account the analyzed fraction of the aerosol flow and the difference between the mass-weighted average NP size and the average size in terms of electrical mobility, which are reduced in the final expression. The calculations 
also use the expression for the total electrode mass loss during the time $T$ as the integral from the mass loss rate by the synthesized NPs:

$$
\Delta M=\int_{0}^{T} \mu(t) d t=A \rho V \frac{\pi}{6} \int_{0}^{T} N(t) D^{3}(t) d t .
$$

Dependences $\mu(t), m_{e}(t)$ and $P_{d}(t)$ calculated from experimental data for the three cases of the degree of electrode asymmetry are shown in Figure 14. The electrical power $P_{d}(t)$ entering the spark gap varies slightly with time except for the first $5 \mathrm{~min}$, during which the working area is heated by SDs. However, the mass loss rate and the energy efficiency are described by steeply and monotonically decreasing functions.

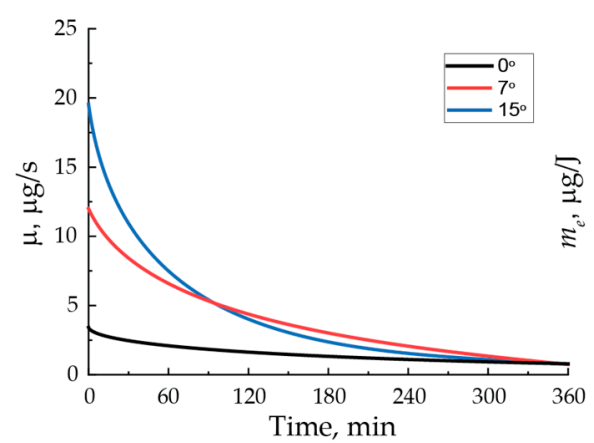

(a)

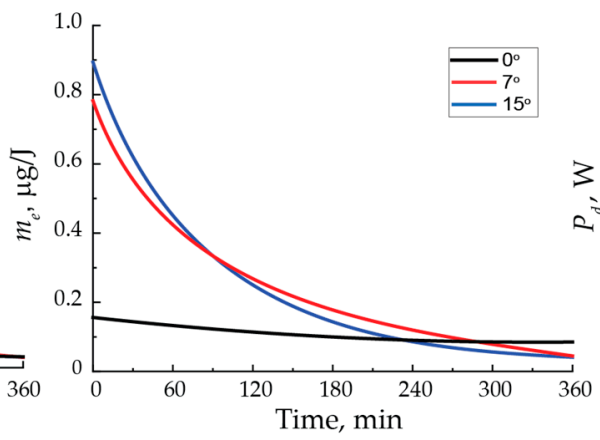

(b)

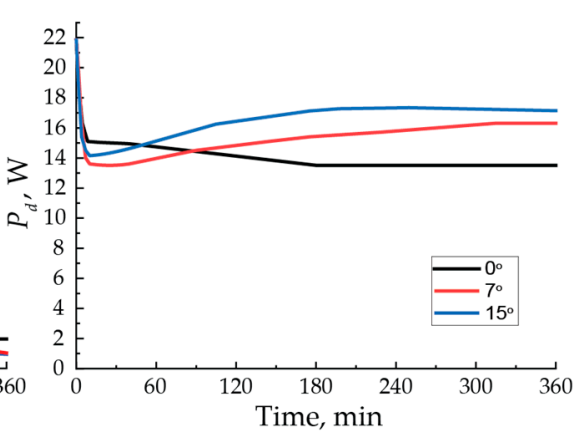

(c)

Figure 14. (a) The electrodes' mass loss rate, (b) energy efficiency, and (c) power released in the spark gap for the three cases of the degree of the electrode asymmetry with the ODP.

The observed effect of the energy efficiency decreasing or of the increasing in the equivalent working area of electrodes' ends initially arranged at an angle correlates qualitatively with the theoretically predicted effect of reducing the energy efficiency of NP synthesis with an increase in the diameter of the electrodes used [21]. Previously, it was noted that a higher mean temperature of electrodes increases mass production $[23,36,40]$ and can lead to an increased production of large particles. This is realized in our experiments at the initial moments of the discharge process between electrodes ends arranged at an angle, when the equivalent working area of electrodes is small and the average density of the discharge current is high.

In experiments with the UDP, even when a cathode end had the angle of $10^{\circ}$, the synthesis of parasitic particles (more than $40 \mathrm{~nm}$ ) was not observed, and the agglomeration of NPs was not significant. This occurred because, in the case of the UDP, the energy released in the spark gap per pulse was almost an order of magnitude less than in the case of the ODP. Therefore, there was no high energy release density even when the discharge was localized between beveled electrodes.

NP arrays on electrodes' end surfaces, as shown in Figure 4e, appeared in the case of an asymmetric arrangement of electrode end faces with the ODP. These surfaces, covered with NPs and not covered with discharge craters, indicate the deposition of a significant part of synthesized NPs back to the electrode and, probably, the transfer from the opposite electrode. Earlier in $[23,36]$, the authors also noted the transfer of large particles to the opposite electrode and the transfer of NPs synthesized from the cathode material on the cathode [41,42].

Our experiments on the NP synthesis by the SD with the UDP, in which the mass of the anode increased (Table 2), clearly indicate the transfer of a significant proportion of synthesized NPs from the cathode to the anode. It is known that in the experiments with the UDP, each electrode works mainly as anode or as cathode and the electrical erosion of the cathode material turns out much higher than that of the anode, which was more accurately 
measured for larger interelectrode gaps in $[43,44]$. The width of the interelectrode gap of about $1 \mathrm{~mm}$ in our work contributed to an increased transfer of synthesized NPs to the opposite electrode. Since the erosion wear of the anode is much less than that of the cathode under these conditions, the material transferred from the cathode compensates the mass loss of the anode and can even increase it.

The origin of protrusions of NP clusters at the anode occurs due to the increased transfer of synthesized NPs from the cathode. These protrusions contribute to the electric field localization and, consequently, increase the probability of an electric breakdown of the gas in front of such protrusions. The growth of such protrusions is unstable, since the highest of them will more likely increase the local electric field and cause subsequent SD from the cathode in its direction. It is this single protrusion that grows and localizes the entire discharge process from the opposite region of the cathode. The growth of such a protrusion can be considered as the unstable process of the SD developing with a positive feedback. Moreover, the discharge process is stopped when the growing protrusion reaches the cathode and forms a conductive metal bridge between electrodes. To avoid instability due to the protrusion growth, it is necessary to create conditions for the removal of synthesized NPs from the interelectrode gap with higher efficiency. To do this, the rate of removal of NPs from the interelectrode gap must be greater than the rate of their synthesis.

Considering all the above, the reason for the absence of effects of the protrusions growth and the closure of the spark gap by a conducting bridge with the ODP becomes clear. In this case, the anode and cathode change their roles at each subsequent half-wave of the discharge current and are almost equal in the intensity of their electrical erosion.

\section{Conclusions}

The main result of this work is the revelation of another important parameter significantly affecting the processes of electrodes electrical erosion and the synthesis of NPs in a pulse-periodic SD-the degree of the electrodes' asymmetry in the rod-to-rod (rod-tothick tube) configuration. It was demonstrated that it is possible to control the size and concentration of synthesized NPs by changing the degree of the electrodes' asymmetry by setting their end faces at a certain angle. With an increase in the degree of the electrodes' asymmetry, larger NPs (with sizes greater than $40 \mathrm{~nm}$ ) appeared in the aerosol composition and their agglomeration increased. This behavior, observed with an increase in the angle between electrodes end faces, is associated with the localization of SD channels in the region of the shortest distance between electrodes and, consequently, with a local increase in the density of the discharge current and in the density of the power released in the discharge.

During the electroerosive wear of asymmetrically arranged electrodes by the ODP, a great part of the end faces of both electrodes became parallel. At the same time, parameters of the synthesized NPs approached those of the NPs synthesized on initially symmetric electrodes. This led to an asymptotic decrease in the average size of NP agglomerates to $150 \mathrm{~nm}$ for the case of the ODP and to $130 \mathrm{~nm}$ for the case of the UDP at the maximum degree of the electrodes' arrangement asymmetry.

In conclusion, it is also important to note that, with the ODP, an increase in the degree of electrodes' asymmetry led to an increased mass production rate and energy efficiency of NP synthesis, and a significant part of this increase was due to the contribution of large NPs with a size of more than $40 \mathrm{~nm}$. Thus, in these regimes a large mass production rate was realized with a sharp deterioration in the qualitative composition of NPs. The parallel arrangement of electrodes' end faces provided the most stable mode of continuous synthesis of NPs of small sizes (less than $40 \mathrm{~nm}$ ), both for the ODP and UDP. It is also important that, in all the cases, a significant proportion of synthesized NPs remained inside the interelectrode gap, settling on electrodes' end faces and not contributing to the energy efficiency of the synthesis. This effect can be minimized by controlling the SDG configuration and the speed parameters of blowing the electrode ends with gas, and by increasing the width of the gap between electrodes. 
The effect of synthesized NP transfer to the opposite electrode with the UDP led to the occurrence of electroerosive instability. It appeared in the form of a protrusion on the anode surface, around which the SD process is localized, causing its further growth This process led to an unstable regime of NP synthesis. As instability developed, the height of the protrusion on the surface of the anode increased, reducing the gap between electrodes. The protrusion grew due to the transfer of the cathode material by synthesized NPs to the area of its formation at the anode. Nevertheless, in the context of individual NP synthesis and the reduction of their agglomeration in the aerosol, the use of UDPs may be promising for practical applications, provided that the electroerosive instability development is prevented. Our further research will be devoted to finding conditions for preventing such instabilities.

Author Contributions: Conceptualization, K.K. and V.I.; Methodology, K.K.; Validation, K.K. and M.U.; Formal Analysis, K.K.; Investigation, K.K. and M.U.; Resources, V.I.; Data Curation, M.U., E.K. and A.L.; Writing-Original Draft Preparation, K.K.; Writing-Review \& Editing, V.I.; Visualization, K.K. and M.U.; Supervision, A.E. and V.I.; Project Administration, V.I.; Funding Acquisition, V.I. and K.K. All authors have read and agreed to the published version of the manuscript.

Funding: This research was funded by RFBR and BRFFR, project number 20-53-00042 in part of the investigation of nanoparticle synthesis with the oscillation-damped discharge pulse and by RFBR, project number 19-33-90202 in part of the investigation of nanoparticle synthesis with the unipolar discharge pulse.

Conflicts of Interest: The authors declare no conflict of interest.

\section{References}

1. Schmidt-Ott, A. Spark Ablation: Building Blocks for Nanotechnology; CRC Press: Boca Raton, FL, USA, 2019; ISBN 978-1-00-073020-3.

2. Kruis, F.E.; Fissan, H.; Peled, A. Synthesis of Nanoparticles in the Gas Phase for Electronic, Optical and Magnetic Applications-A Review. J. Aerosol Sci. 1998, 29, 511-535. [CrossRef]

3. Scheeline, A.; Coleman, D.M. Direct Solids Elemental Analysis: Pulsed Plasma Sources. Available online: https://pubs.acs.org/ doi/pdf/10.1021/ac00147a001 (accessed on 9 March 2021).

4. Mylnikov, D.; Efimov, A.; Ivanov, V. Measuring and Optimization of Energy Transfer to the Interelectrode Gaps during the Synthesis of Nanoparticles in a Spark Discharge. Aerosol Sci. Technol. 2019, 53, 1393-1403. [CrossRef]

5. Kohut, A.; Villy, L.P.; Ajtai, T.; Geretovszky, Z.; Galbács, G. The Effect of Circuit Resistance on the Particle Output of a Spark Discharge Nanoparticle Generator. J. Aerosol Sci. 2018, 118, 59-63. [CrossRef]

6. Evans, D.E.; Harrison, R.M.; Ayres, J.G. The Generation and Characterisation of Elemental Carbon Aerosols for Human Challenge Studies. J. Aerosol Sci. 2003, 34, 1023-1041. [CrossRef]

7. Byeon, J.H.; Park, J.H.; Hwang, J. Spark Generation of Monometallic and Bimetallic Aerosol Nanoparticles. J. Aerosol Sci. 2008, 39, 888-896. [CrossRef]

8. Vons, V.A.; de Smet, L.C.P.M.; Munao, D.; Evirgen, A.; Kelder, E.M.; Schmidt-Ott, A. Silicon Nanoparticles Produced by Spark Discharge. J. Nanopart. Res. 2011, 13, 4867. [CrossRef]

9. Lizunova, A.A.; Mylnikov, D.A.; Efimov, A.A.; Ivanov, V.V. Synthesis of Ge and Si Nanoparticles by Spark Discharge. J. Phys. Conf. Ser. 2017, 917, 032031. [CrossRef]

10. Mardanian, M.; Nevar, A.A.; Nedel'ko, M.; Tarasenko, N.V. Synthesis of Colloidal CuInSe2 Nanoparticles by Electrical Spark Discharge in Liquid. Eur. Phys. J. D 2013, 67, 208. [CrossRef]

11. Lee, D.-J. Highly Efficient Synthesis of Semiconductor Nanoparticles Using Spark Discharge. Ph.D. Thesis, Graduate School, Seoul National University, Seoul, Korea, 2018.

12. Tseng, K.-H.; Chang, C.-Y.; Chung, M.-Y.; Cheng, T.-S. Fabricating TiO2nanocolloids by Electric Spark Discharge Method at Normal Temperature and Pressure. Nanotechnology 2017, 28, 465701. [CrossRef]

13. Takao, Y.; Awano, M.; Kuwahara, Y.; Murase, Y. Preparation of Oxide Superconductive Composite by an Electrostatic Mixing Process. Sens. Actuators B Chem. 1996, 31, 131-133. [CrossRef]

14. Chadda, S.; Ward, T.L.; Carim, A.; Kodas, T.T.; Ott, K.; Kroeger, D. Synthesis of $\mathrm{YBa}_{2} \mathrm{Cu}_{3} \mathrm{O}_{7-\gamma}$ and $\mathrm{YBa}_{2} \mathrm{Cu}_{4} \mathrm{O}_{8}$ by $\mathrm{Aerosol}$ Decomposition. J. Aerosol Sci. 1991, 22, 601-616. [CrossRef]

15. Efimov, A.A.; Potapov, G.N.; Nisan, A.V.; Ivanov, V.V. Controlled Focusing of Silver Nanoparticles Beam to Form the Microstructures on Substrates. Results Phys. 2017, 7, 440-443. [CrossRef]

16. Volkening, F.A.; Naidoo, M.N.; Candela, G.A.; Holtz, R.L.; Provenzano, V. Characterization of Nanocrystalline Palladium for Solid State Gas Sensor Applications. Nanostructured Mater. 1995, 5, 373-382. [CrossRef]

17. Ivanov, V.V.; Efimov, A.A.; Myl'nikov, D.A.; Lizunova, A.A. Synthesis of Nanoparticles in a Pulsed-Periodic Gas Discharge and Their Potential Applications. Russ. J. Phys. Chem. 2018, 92, 607-612. [CrossRef] 
18. Mohammed, A.M. Fabrication and Characterization of Gold Nano Particles for DNA Biosensor Applications. Chin. Chem. Lett. 2016, 27, 801-806. [CrossRef]

19. Khabarov, K.M.; Kornyushin, D.V.; Masnaviev, B.I.; Tuzhilin, D.N.; Efimov, A.A.; Saprykin, D.L.; Ivanov, V.V. Laser Sintering of Silver Nanoparticles Deposited by Dry Aerosol Printing. J. Phys. Conf. Ser. 2019, 1410, 012217. [CrossRef]

20. Khabarov, K.; Kornyushin, D.; Masnaviev, B.; Tuzhilin, D.; Saprykin, D.; Efimov, A.; Ivanov, V. The Influence of Laser Sintering Modes on the Conductivity and Microstructure of Silver Nanoparticle Arrays Formed by Dry Aerosol Printing. Appl. Sci. 2020 10, 246. [CrossRef]

21. Domaschke, M.; Schmidt, M.; Peukert, W. A Model for the Particle Mass Yield in the Aerosol Synthesis of Ultrafine Monometallic Nanoparticles by Spark Ablation. J. Aerosol Sci. 2018, 126, 133-142. [CrossRef]

22. Feng, J.; Biskos, G.; Schmidt-Ott, A. Toward Industrial Scale Synthesis of Ultrapure Singlet Nanoparticles with Controllable Sizes in a Continuous Gas-Phase Process. Sci. Rep. 2015, 5, 15788. [CrossRef]

23. Tabrizi, N.S.; Ullmann, M.; Vons, V.A.; Lafont, U.; Schmidt-Ott, A. Generation of Nanoparticles by Spark Discharge. J. Nanopart. Res. 2008, 11, 315. [CrossRef]

24. Ivanov, V.V.; Efimov, A.A.; Mylnikov, D.A.; Lizunova, A.A.; Bagazeev, A.V.; Beketov, I.V.; Shcherbinin, S.V. High-Efficiency Synthesis of Nanoparticles in a Repetitive Multigap Spark Discharge Generator. Tech. Phys. Lett. 2016, 42, 876-878. [CrossRef]

25. Lizunova, A.; Mazharenko, A.; Masnaviev, B.; Khramov, E.; Efimov, A.; Ramanenka, A.; Shuklov, I.; Ivanov, V. Effects of Temperature on the Morphology and Optical Properties of Spark Discharge Germanium Nanoparticles. Materials 2020, $13,4431$. [CrossRef]

26. Yang, F.; Bellotti, M.; Hua, H.; Yang, J.; Qian, J.; Reynaerts, D. Experimental Analysis of Normal Spark Discharge Voltage and Current with a RC-Type Generator in Micro-EDM. Int. J. Adv. Manuf. Technol. 2018, 96, 2963-2972. [CrossRef]

27. D'Urso, G.; Maccarini, G.; Quarto, M.; Ravasio, C.; Caldara, M. Micro-Electro Discharge Machining Drilling of Stainless Steel with Copper Electrode: The Influence of Process Parameters and Electrode Size. Adv. Mech. Eng. 2016, 8. [CrossRef]

28. Ahmad, S.; Laiho, P.; Zhang, Q.; Jiang, H.; Hussain, A.; Liao, Y.; Ding, E.-X.; Wei, N.; Kauppinen, E.I. Gas Phase Synthesis of Metallic and Bimetallic Catalyst Nanoparticles by Rod-to-Tube Type Spark Discharge Generator. J. Aerosol Sci. 2018, 123, 208-218. [CrossRef]

29. Han, K.; Kim, W.; Yu, J.; Lee, J.; Lee, H.; Gyu Woo, C.; Choi, M. A Study of Pin-to-Plate Type Spark Discharge Generator for Producing Unagglomerated Nanoaerosols. J. Aerosol Sci. 2012, 52, 80-88. [CrossRef]

30. Trad, M.; Nominé, A.; Tarasenka, N.; Ghanbaja, J.; Noël, C.; Tabbal, M.; Belmonte, T. Synthesis of Ag and Cd Nanoparticles by Nanosecond-Pulsed Discharge in Liquid Nitrogen. Front. Chem. Sci. Eng. 2019, 13, 360-368. [CrossRef]

31. Schwyn, S.; Garwin, E.; Schmidt-Ott, A. Aerosol Generation by Spark Discharge. J. Aerosol Sci. 1988, 19, 639-642. [CrossRef]

32. Megyeri, D.; Kohut, A.; Geretovszky, Z. Effect of Flow Geometry on the Nanoparticle Output of a Spark Discharge Generator. J. Aerosol Sci. 2021, 154, 105758. [CrossRef]

33. Handbook of Physics; Benenson, W.; Harris, J.W.; Stöcker, H.; Lutz, H. (Eds.) Springer: Berlin/Heidelberg, Germany, 2002; ISBN 978-0-387-95269-7.

34. Jüttner, B. Cathode Spots of Electric Arcs. J. Phys. D Appl. Phys. 2001, 34, R103-R123. [CrossRef]

35. Mesyats, G.A.; Bochkarev, M.B.; Petrov, A.A.; Barengolts, S.A. On the Mechanism of Operation of a Cathode Spot Cell in a Vacuum Arc. Appl. Phys. Lett. 2014, 104, 184101. [CrossRef]

36. Kohut, A.; Wagner, M.; Seipenbusch, M.; Geretovszky, Z.; Galbács, G. Surface Features and Energy Considerations Related to the Erosion Processes of $\mathrm{Cu}$ and Ni Electrodes in a Spark Discharge Nanoparticle Generator. J. Aerosol Sci. 2018, 119, 51-61. [CrossRef]

37. Parkevich, E.V.; Ivanenkov, G.V.; Medvedev, M.A.; Khirianova, A.I.; Selyukov, A.S.; Agafonov, A.V.; Mingaleev, A.R.; Shelkovenko, T.A.; Pikuz, S.A. Mechanisms Responsible for the Initiation of a Fast Breakdown in an Atmospheric Discharge. Plasma Sources Sci. Technol. 2018, 27, 11LT01. [CrossRef]

38. Parkevich, E.V.; Medvedev, M.A.; Khirianova, A.I.; Ivanenkov, G.V.; Selyukov, A.S.; Agafonov, A.V.; Shpakov, K.V.; Oginov, A.V. Extremely Fast Formation of Anode Spots in an Atmospheric Discharge Points to a Fundamental Ultrafast Breakdown Mechanism. Plasma Sources Sci. Technol. 2019, 28, 125007. [CrossRef]

39. Hinds, W.C.; Hinds, W.C. Aerosol Technology: Properties, Behavior, and Measurement of Airborne Particles; Wiley: Hoboken, NJ, USA, 1999; ISBN 978-0-471-19410-1.

40. Feng, J. Scalable Spark Ablation Synthesis of Nanoparticles: Fundamental Considerations and Application in Textile Nanofinishing. Ph.D. Thesis, Delft University of Technology, Delft, The Netherlands, 2016. [CrossRef]

41. Petrov, A.A.; Amirov, R.H.; Samoylov, I.S. On the Nature of Copper Cathode Erosion in Negative Corona Discharge. IEEE Trans. Plasma Sci. 2009, 37, 1146-1149. [CrossRef]

42. Amirov, R.H.; Petrov, A.A.; Samoylov, I.S. Nanoparticles Formation and Deposition in the Trichel Pulse Corona. J. Phys. Conf. Ser. 2013, 418, 012064. [CrossRef]

43. Cundall, C.M.; Craggs, J.D. Electrode Vapour Jets in Spark Discharges. Spectrochim. Acta 1955, 7, 149-164. [CrossRef]

44. Hemmi, R.; Yokomizu, Y.; Matsumura, T. Anode-Fall and Cathode-Fall Voltages of Air Arc in Atmosphere between Silver Electrodes. J. Phys. D Appl. Phys. 2003, 36, 1097-1106. [CrossRef] 